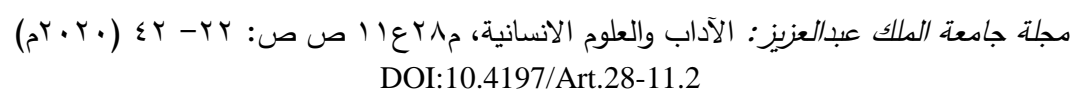

\title{
الأبنية الصرفية "يَفْتَعِل" "تَفَاعَل" "مَفْعَل" ودورها الدلالي في الكلمة القرآنية دراسة تحليلية استقرائية
}

\section{د. علي خليفة عطوة عبداللطيف

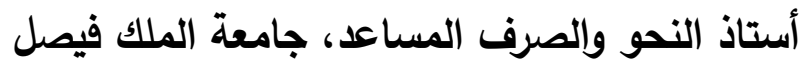

الأحساء، المملكة العربية السعودية ولهية

مستخلص. تظهر مشكلة الدراسة من خلال وجود خلاف بين كتب تفسير القرآن الكريم حول الأبنية الصرفية

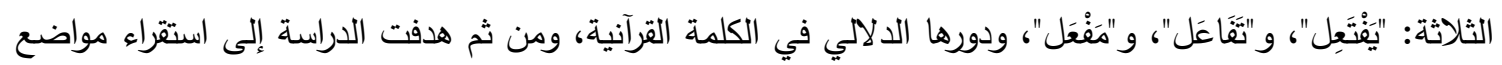

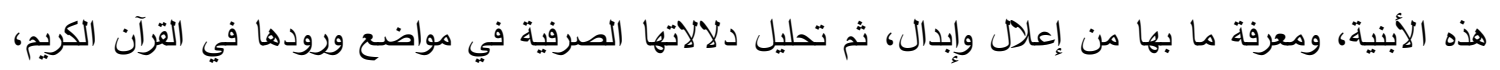

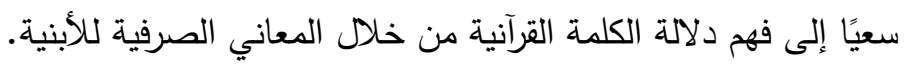

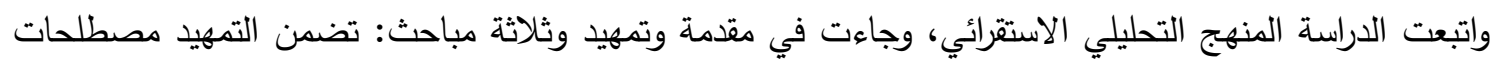

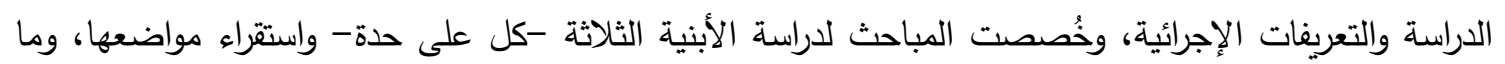

حدث فيها من حذف وقلب وإدغام، مع تحليل دلالاتها الصرفية.

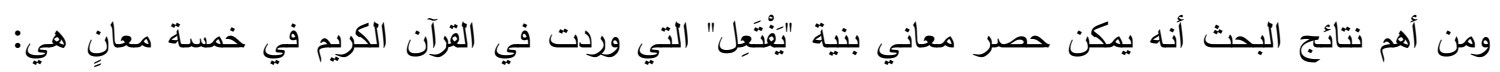

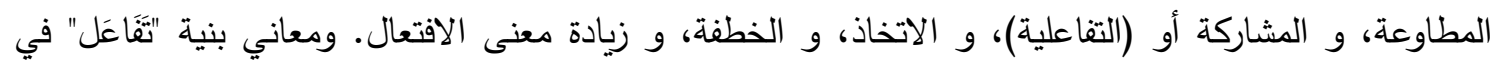

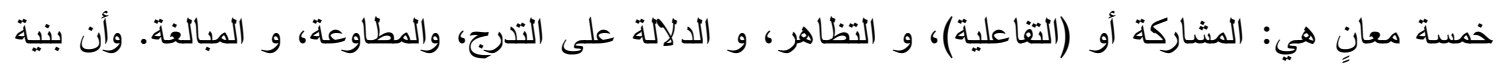

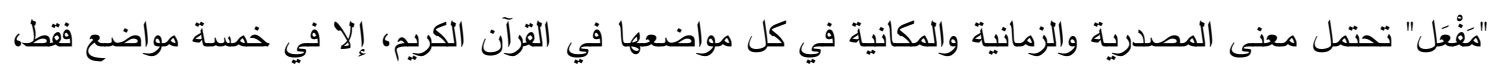

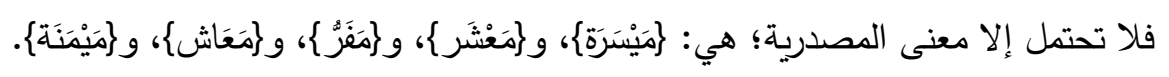

الكلمات المفتاحية: الفعل اللازم، الفعل المتعدي، الفعل المجرد.

الآلة، واسم الفاعل، واسم المفعول، وصيغ المبالغة، والصِّفة المشبَّهة، واسم التَّتضيل.

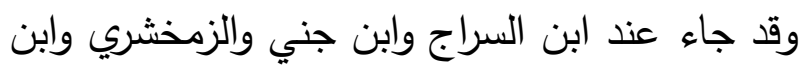
يعيش وابن الحاجب والسهيلي والرضي وغيرهم، ولن ولني بعض اللمحات الكاشفة عن دلالة بعض الأبنية

\section{المقدمة}

استتبط الصَّرفيُّون قوالب صَرفية للأسماء والأفعال؛ محَّة

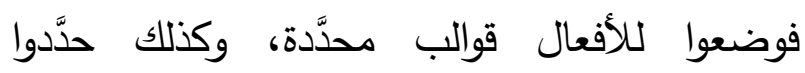
للأسماء قوالب معروفة، بما فيها المصدر واسم الزَّمان واسم المكان، واسم المرَّة، واسم الهيئة، واسم 
مواضع الأبنية الصرفية الثلاثة، ومعرفة ما بها من إعلال وإبدال، ثم تحليل دلالاتها الصرفية في كل مواضع ورودها في القرآن الكريم، من خلال محاولة دلة الإجابة عن الأسئلة الآتية:-

* أسئلة الاراسة:

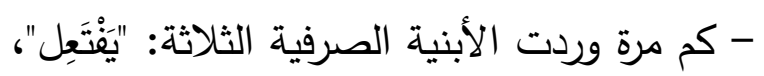

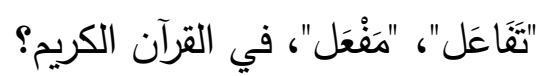

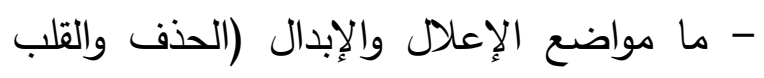
والإدغام) في الأبنية الصرفية الثلاثة في القرآن الكريم؟

- ما معاني الأبنية الصرفية الثلاثة الواردة في القرآن الكريץ? مان؟

- كم مرة ورد كل معنى من معاني الأبنية

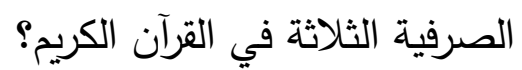

- ما أكثر معاني الأبنية الصرفية الثلاثة ورودًا

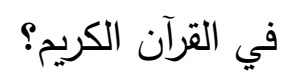

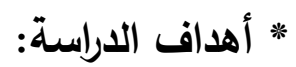

- استقراء مواضع ورود الأبنية الصرفية الثلاثة في القرآن الكريم.

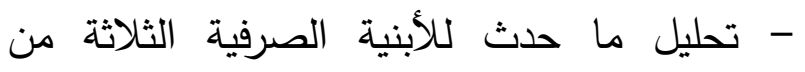
الحذف والقلب والإدغام في القرآن الكريم.

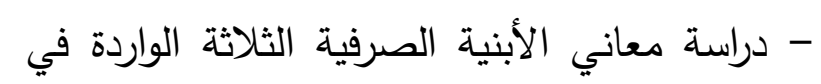
القرآن الكريץ.

- ترجيح مواضع ورود كل معنى من معاني الأبنية الصرفية الثلاثة في القرآن الكريخ.

- معرفة أكثر معاني الأبنية الصرفية الثلاثة ورودًا

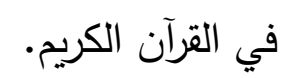

الصرفية بما يميز كل بنية عن الأخرى، ثم جاء

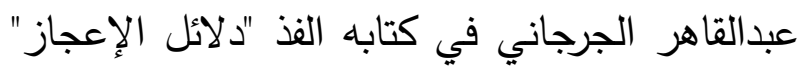

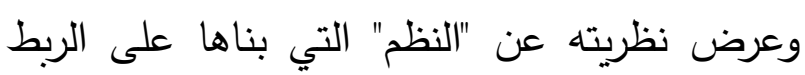

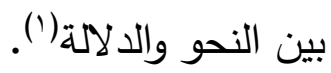

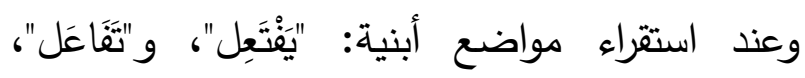
و" "تَفْعَل، في القرآن الكريم نجد أن هنالك خلافًا بين المفسرين مبنيَّا حول الدلالة الصرفية لهذه الأبنية؛

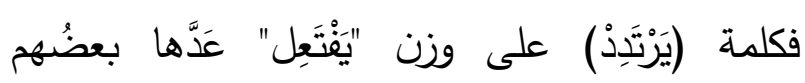

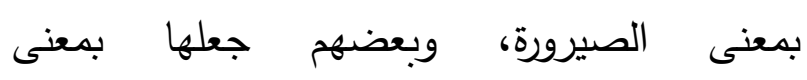

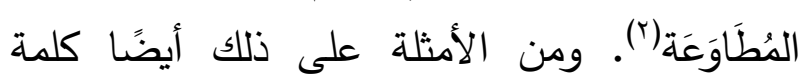

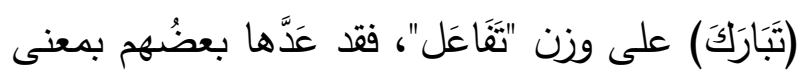

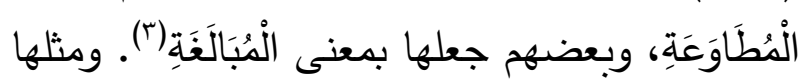

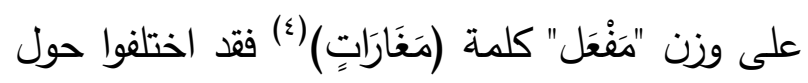

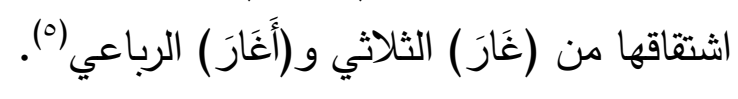

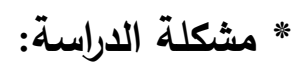
تظهر مشكلة الدراسة من خلال وجود خلاف بين المفسرين ينبني على الخلاف حول الأبنية الصرفية

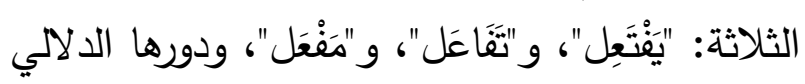
في الكلمة القرآنية، وتتمثل مشكلة الدراسة في استقراء ولفئل ودورهاء

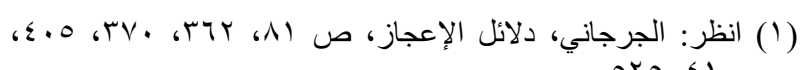

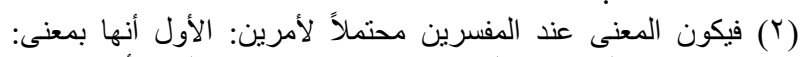

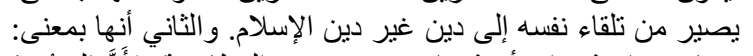

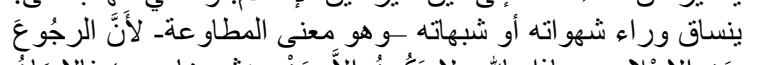

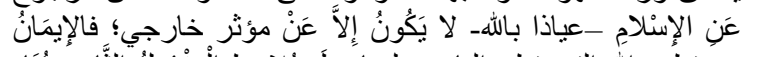

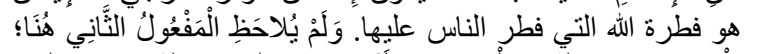

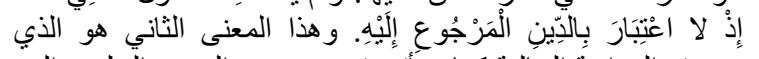

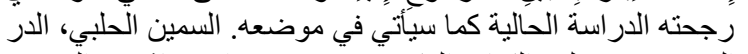

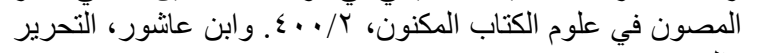
و التتوير، ك/ بكس.

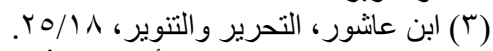

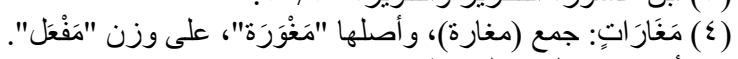

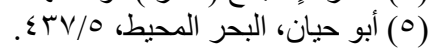


المصادر، و(اسم الفاعل، اسم المفعول، الصفة المشبهة، صيغ المبالغة) من المشتقات. وقد أفادت الدراسة الحالية من تلك الدراسة من الناحية النظرية فيما يتعلق بصيغة "افْتَعَلَ". * إجراءات الاراسةة: - منهج الدراسة: اتبعت الدراسة المنهج التحليلي الاستقرائي لملاعمته لأهداف الدراسة. - خطوات الدراسة: جاءت الدراسة في مقدمة وتمهيد وثلاثة مباحث: تضمن التمهيد مصطلحات الدراسة والتعريفات الإجرائية، وخُصصت المباحث لدراسة الأبنية الثلاثة، واستقراء مواضعها، وما حدث فيها من حذف وقلب وإدغام، مع تحليل دلالاتها الصرفية، فتتاول المبحث الأول "يَفْتَعِل"، والثاني "تَفَاعَل"، والثالث "مَفْعَل"، ثم خُتمت الدراسة بالنتائج وقائمة المراجع. ولم تعرض الدراسة لذكر لتراجم الأعلام؛ لأنها مذكورة في مظانها من كتب التراجم المعروفة، ولأن الالتزام بذلك من مقتضيات تحقيق المخطوطات، وليس من مقتضيات التأليف العلمي، كما أن في ذلك حفاظا على البحث من الاستطراد. * تمهيد: مصطلحات الدراسة والتعريفات

\section{الإجرائية: أن}

- الأبنية الصرفية: كلمة "الأبنية" في اللغة: جمع "بِنْية" بالكسر أو "بُنْية" بالضم أو "بناء"، وهي مشتقة من المصدر "البني" الذي هو نقيض الهدم" وفعله "بنى"، ومنه "بنى البناء بناء، يبني بنيًا وبنَى وبنيانًا
* أهمية الدراسةة:

- استكمال نهج الدراسات الصرفية القرآنية. - استقراء مواضع الأبنية الصرفية الثلاثة في القرآن الكريم. - دراسة الأبنية الصرفية الثلاثة دراسة تحليلية. - السعي إلى فهم دلالة الكلمة القرآنية من خلال المعاني الصرفية للأبنية. * الدراسات السابقة: ظهرت جهود علمية كبيرة تتاولت الأبنية الصرفية لكلمات القرآن، كان أكثرها صلة بموضوع الدراسة الحالية: دراسة "دور الصرف في الكثف عن دلالات الكلمة القرآنية" توفيق حمارشة (997 (م) التي اقتصرت على صيغة "فَعَّلَ"، ثم أعقبتها دراسة أخرى سنة 99 ام للباحث نفسه تناول فيها صيغة "أَفْعَلَ". ثم جاءت دراسة "الأبنية الصرفية في السور المدنية دراسة لغوية دلالية" سنة س...rام، وهي رسالة ماجستير من إعداد الطالبة عائشة قشوع، تتاولت فيها الأبنية الصرفية في السور المدنية بدراسة وصفية أشبه ما تكون بالعمل المعجمي، دون أن يعرض للجانب التحليلي أو الدلالي. وتأتي دراسة "الميزان الصرفي في لسان القرآن" لراتب السمان

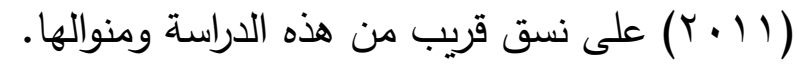
وآخر هذه الدراسات هي دراسة "أثر تتوع الصيخ الصرفية في إيضاح المقاصد القرآنية" سنة م | • بم، وهي رسالة ماجستير من إعداد الطالبين بشير فوضيل وخيرالدين لمونس، تتاولا فيها من الأفعال

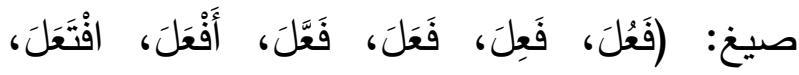
اسْتَفْعَلَ)، ومن الأسماء صيخْ (فِعَالَةَ، فَعَلانَ) من 
- الدلالة الصرفية: الدلالة الصرفية أو المعنى الصرفي هي: دارسة التركيب الصرفي للكلمة وبيان المعنى الذي تؤديه صيغتها.. فلا يكفي لبيان معنى "

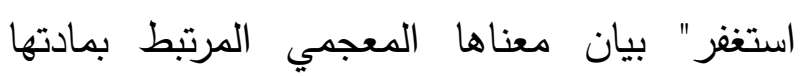
اللغوية (غ ف ر) بل لابد أن يضم إلى ذلك معنى الصيغة وهي هنا وزن (استفعل) أو الألف والسين

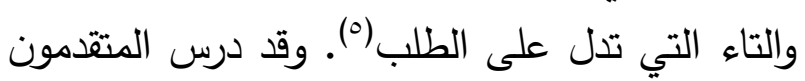
جوانب مختلفة من الدلالة الصرفية، وقدموا لمحات كاشفة فيها، ومن ذلك ما نقرؤه من كلامهر عن من من صيخ تدل على "الاضطراب والحركة وهي صيغة

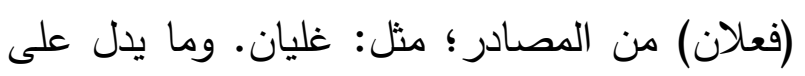

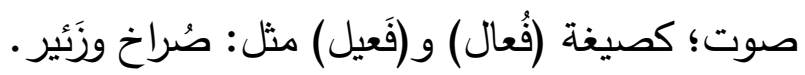
وما يدل على لون؛ كصيغة (فُعلة) مثل: حُمرة. وما يدل على حرفة؛ كصيغة (فِعالة) مثل: زِراعة"(؟). ومثل "فََّال" لكل محترف صاحب صنعة يزاولها ويديمها ونان.

ويعقد ابن جني بابا حول "الدلالة اللفظيّة والصناعيّة والمعنويَّة" وهو يقصد بـ "الدلالة الصناعيّة" "دلالة الصيغة" ويراها أقوى من "الدلالة المعنويَّة"- يقول: "ومن ذلك قولهم للسُلَّم "مِرْقاة" وللدرجة "مَرَقاة" فنفس ونس اللفظ يدلّ على الحدث الذي هو الرقيّ، وكسر الميم يدلّ على أنها مما ينقل ويعتمل عليه وبـ؛ كالمِطرقة

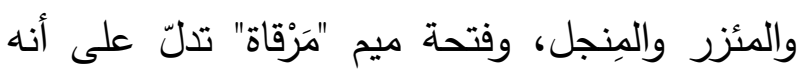
مستقرِ في موضعه كالمنارة والمثابة. ولو كانت ملت ملت

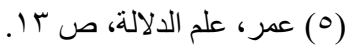

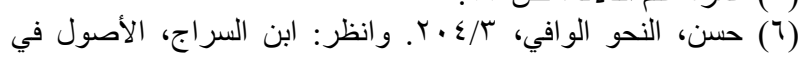

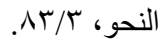

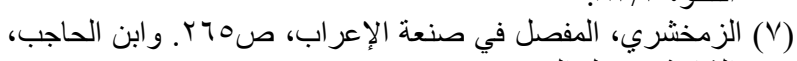

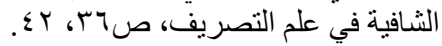

وبناية"(1). وأما "الأبنية" الصرفية: فهي صيخ الكلمات التي تنشأ عن التصريف الذي هو جعل الكلمة على صيغ مختلفة لضروب من المعاني، وهي حروف الكلمة وحركاتها وسكناتها. فبنية الكلمة وبناؤها ومبناها كلها ألفاظ مترادفة تعني عدة وهات الحروف مع الهيئة التي تكون عليها؛ فبنية الفعل "نزل" تعني حروفه التي يتكون منها، والهيئة التي تتتظم هذه الحروف من حركة أو سكون. وأي تغير في مبنى الكلمة أو بنيتها سواء كان بالزيادة أو هن النقصان، يتبعه تغير في معنى الكلمة ومدلولها ومفهومها وما ترمي إليه. فكلمة "غفر" تدل على فيلى وقوع الغفران، فإذا ما زيد عليها همزة وسين وتاء وصارت "استغفر " كان معناها طلب المغفرة(؟). - الدلالة: الدلالة لغة: مصدر الفعل دلّ يدُلُّ، وهو يدور حول إبانة الثيء بأمارٍٍ تتعلّمها، تقول: دلَلْتُ

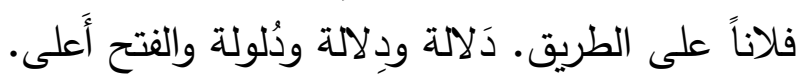

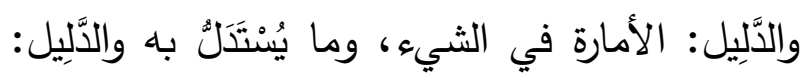

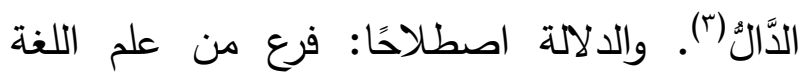
يدرس الشروط الواجب توافرها في الرمز حتى يكون قادرًا على حمل المعنى. وهذا الرمز قد يكون علامة على طريق أو إشارة بيد أو كلمة أو جملة، فهو رمز لغوي أحيانًا وغير لغوي أحيانًا أخرى (؟).

( (1) انظر : ابن فارس، معجم مقاييس اللغة (ب ن ي). وابن منظور، د.ت،

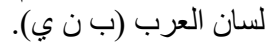

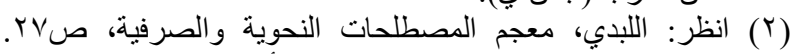

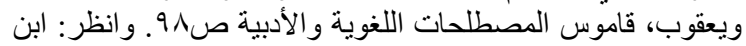

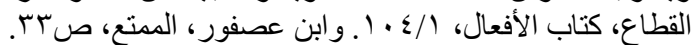

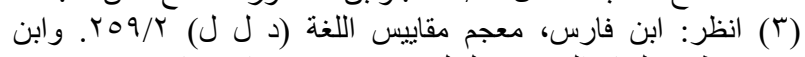

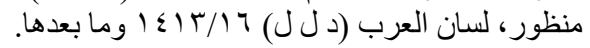

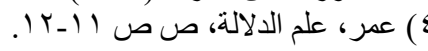


العضديات"، والرضي في "شرح شافية ابن الحاجب"،

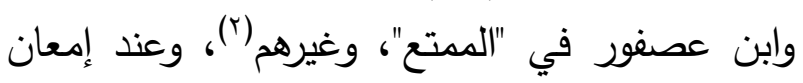
النظر في هذه المعاني نجد بعضها متداخلا في دلالته، أو نجد أن المسمى واحد والمصطلح مختلف؛ فمثلاً نجد مجيء بنية "يَفْتَعِل" للفعل المضارع بمعنى "تفاعل" مع اشتراك فاعلين فيه، يسميهم بعضهم "مشاركة"، ويسميه آخرون "تفاعلية"، ولا مشاحة في

\section{|لاصطلاح.}

* مواضعها في القرآن الكريم: جاء وزن "يَفْتَعل" في اثنتين وستين كلمة في القرآن الكريخ؛ يجمعها الجدول الآتي (r):

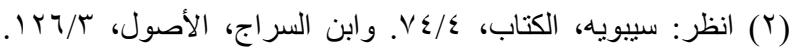

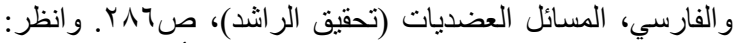

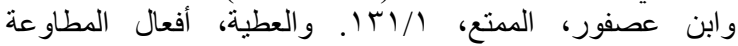

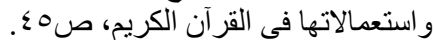

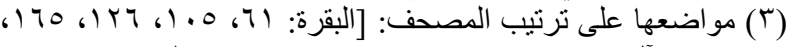

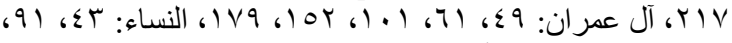

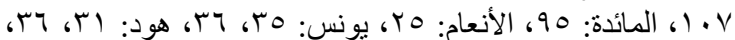

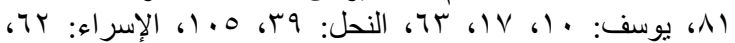

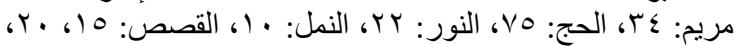

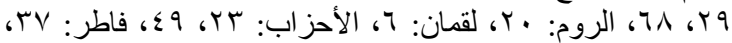

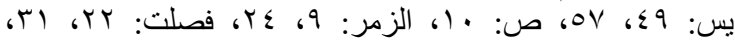

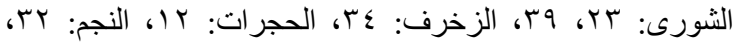

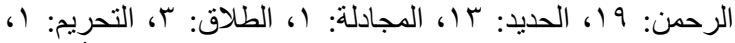

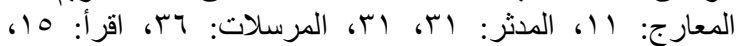

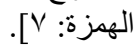

المنارة ممَّا يجوز كسر ميمها لوجب تصحيح عينها وأن تقول فيها "مِنْوَرة" لأنه كانت تكون حينئذ منقوصة من مثال "مِفعال" كمِزْوَحة ومِسْوَرة ومِعْول ومِجْول. فنفْس (ر ق ي) يفيد معنى الارتقاء، وكسرة الميم وفتحتها تدلأَن على ما قدّمناه من معنى الثبات أو الانتقال. وكذلك (الضرب) و(القتل): نفس اللفظ يفيد الحدث فيهما، ونفس الصيغة تفيد فيهما صلاحهما للأزمنة الثلاثة على ما نقوله في المصادر • وكذلك اسم الفاعل - نحو قائم وقاعد لفظه يفيد الحدث الذي هو القيام والقعود وصيغته وبناؤه يفيد كونه صاحب الفعل. وكذلك (قَطَّع) و(كسَّر) فنفس اللفظ هاهنا يفيد معنى الحدث، وصورته تقيد شيئين: أحدهما الماضي، والآخر تكثير الفعل. كما أن (ضارَب) يفيد بلفظه الحدث، وِبنِائه الماضي وكونَ الفعل من اثثين، وبمعناه على أن لله فاعلا. فتلك أربعة معانٍ. فاعرف ذلك إلى ما يليه فإنه كثير لكن هذه طريقه"('). وهذه العبارة الأخيرة لابن جني "فاعرف ذلك إلى ما يليه فإنه كثير لكن هذه طريقه" تفتح الباب للبحث في دلالات الصيخ. المبحث الأول: "يَفْتَعِل" ومواضعها في القرآن الكريم بنية "يَفْتَعِل" يأتي عليها الفعل المضارع لازما ومتعديا، فاللازم نحو "يفتقر"، والمتعدي نحو

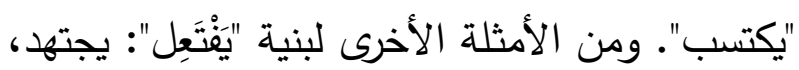
يدّخر ، يستلم، يقتصد، يلتحق، يلتمس. ولبنية "يَفْتَعِل" معانٍ كثيرة تناولها سيبويه في كتابه، وابن السراج في "الأصول"، والفارسي في "المسائل 
جدول (1): الكلمات التي جاءت على وزن "يَفْتَعِل" في القرآن الكريم

\begin{tabular}{|c|c|c|c|c|c|}
\hline الموضع & الكلمة & الموضع & الكلمة & الموضع(') & الكلمة \\
\hline أَضْطَرَرُهُ & يَضْطَرَ & يَخْتَصُُ & يَخْنَصُُ & يَعْتَدُونَ & يَعْنَدَي \\
\hline تَدَّْرُونَ & يَدَّخر & يَرْتَدِدْ & يَرْتَدَدْ & يَتََّذْذُ & يَتَّذذذ \\
\hline لَيَتِتَلَيَكُمْ & يَيْتَلِي & يَعْتَهِم & يَعْتَصِم & نَبْتَهِكِنْ & يَيَتَهِلِل \\
\hline يَعْتَزَلُوكُكْ & يعتزل & تَغْتَبِلُوا & يغتسل & يَجْتَبَي & يَجْنَبَي \\
\hline يَسْنَتَعِعُ & يَسْتَعِع & فَيَتَتَِِعُ & ينتقم & يَخْتَانُونَ & يَخْتَان \\
\hline تَزَدَرِي & يَزْدَرِي & يَهِدِيّي & يهتدي & يُتَتَبَعَ & يَتَّعِع \\
\hline يَلْتَفَطْهُهُ & يلتقط & يَلْتَفِتْتُ & يلتقت & تَبتَتَبَسْن & يَبْتَسَس \\
\hline يَخْتَلَفُونَ & يَخْتَلِف & نَكْتَلْ & يكتال (r) & نَسَنَتَقِقُ & يَسْنَتَِق \\
\hline يَمْتَرُونَ & يمتري & لَأَخْتَنَكَنَّنَ & يَحْنَتِكِ & يَفْتَرِي & يفتري \\
\hline تَهْتَزَّ & يهتز & يَأْتَلِ & يَأَتْلِي & يَصْطَفِي & يَصْطَفِي \\
\hline تَصْطَلَونَ & يَصْطَلِي & يَأْتَمِرُونَ & يَأْتَمِر & يَقْتَتِلَانِ & يقتل \\
\hline يَثْتَتَري & يَشْتَرَيِ & تَتَتَشْرُونَ & ينتشر & يَخْتَارُ & يَخْتَار \\
\hline يَصْطَرِخِونَ & يَضْطَرِخ & تَعْتَدُّونَهَا & يَعَتَّت & يَنَظظرِرُ & ينتظر \\
\hline فَلَيْرَتَقُوا & يَرَتَتَي & يَدَّعُونَ & يَََّعي & يَخِمِِمُونَ & يَخْتَسِم \\
\hline تَسْنَتَرْرُونَ & يَسْتَتِرِ & يَتَّقِي & يَتَِِّي & يَسْنَوِي & يَسْنَوِي \\
\hline يَنتَهِرُونَ & يَنتَهِرِ & يَقْتَرَفْ & يَقْتَرَف & تَتْتَتَهِي & يَثْتَتَهِي \\
\hline يَجْتَنَبُونَ & يَجْتَنَب & يَغْتَب & يَغْتَبَ (r) & يَتَّكَيُونَنَ & يَتَّكئُ \\
\hline تَثْنَكِي & يَشْتَكِي & نَقْتَبَسن & يقتتَبِس & يَلْتَتَيَانِ & يَلْتَقِي \\
\hline يَفْتَدَي & يَفْتَدي & تَبَتَغَغي & يَبْتَغني & يَحْتَسِبُ & يَحْتَسِب \\
\hline \multirow[t]{2}{*}{ فَيَعْنَتَرْرونَ } & يَعْنَتَرِ & يَرْنَابَ & يَرْنَاب & يَزَدَدَدَ & يَزْدَاد \\
\hline & & تَطَّلَعُ & يَطَّلَعِ & يَنتَهِهِ & ينتهي \\
\hline
\end{tabular}

* الحذف والقلب والإدغام في مواضع بنية "يَفْتَعِ" في القرآن الكريم:

( (1) نظرًا للتقيد بعدد الصفحات لم تستطع الدر اسة ذكر نص الآيات كاملة، و اكتقت بتخريجها كما في الهامش السابق.

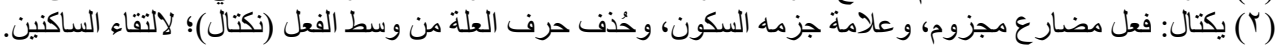

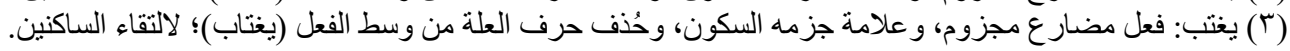




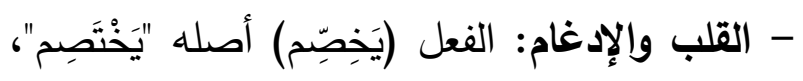

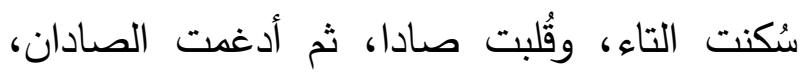
فأصبحتا صادًا مشددة، وكسرت الخاء تخلصا من التاء التثقاء الساكنين. و و(يدعي) أصله "يَتَنَعِي"، قُلبت التَاء

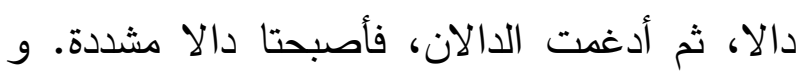

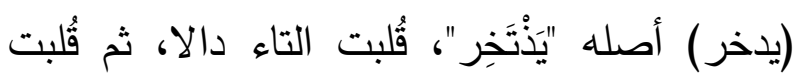
الذال أيضا دالا، ثم أدغمت الدالان، فأصبحتا دالا لالا

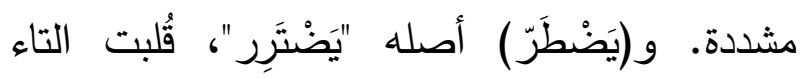

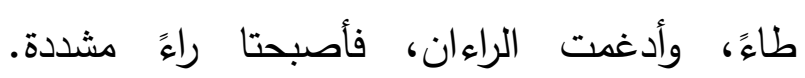

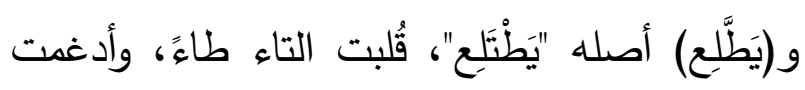

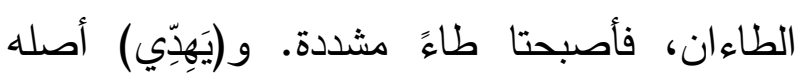

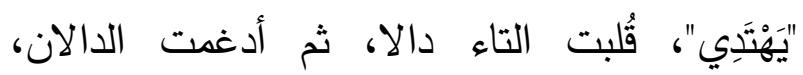
فأصبحتا دالا مشددة، وكسرت الهاء تلاء تخلصا من الهاء

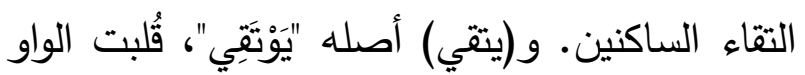
تاء، ثم أدغت التاءان، فأصبحتا تاء مشددة.

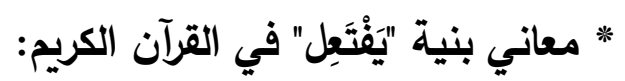

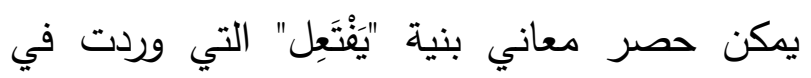
القرآن الكريم في خمسة معانٍ هي:1- معنى المطاوعة: وهو أن يكون قائما مقام

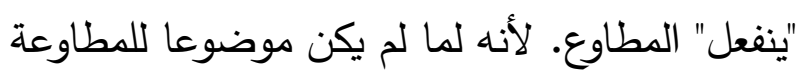

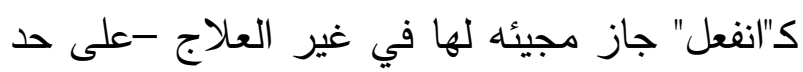

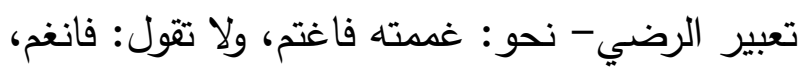

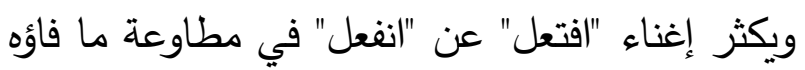

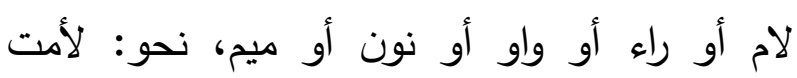

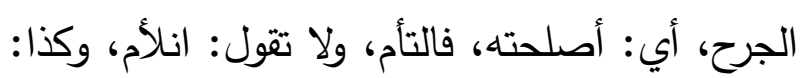

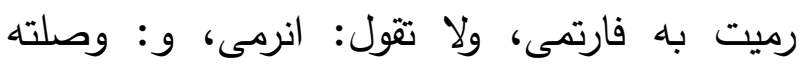

- حذف حرف العلة: جاء في الفعل (يَأْتل)ِ)، والفعل (ينتَّ)، وعلامة جزمهما حذف حرف العلة (الياء).

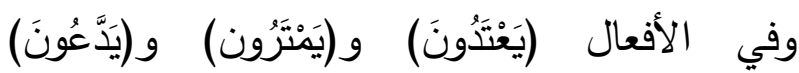
و(يَرتَثُوا) حُذف حرف الافعال لكلاتصال بواو الجماعة. - القلب: جاء في (يختان) أصله "تَخَفْوَن"، وقُلبت الواو ألف مد. وفي (يختار) أصله "يَخْتَتِر"، وقُلبت

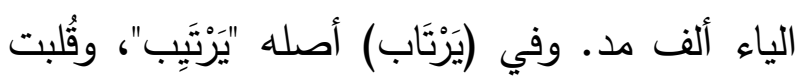

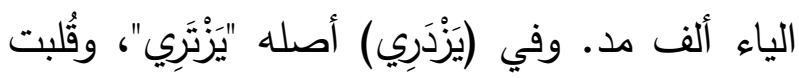

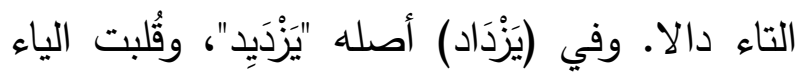

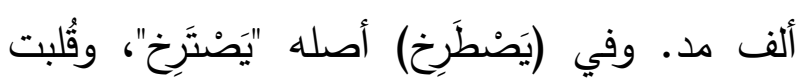

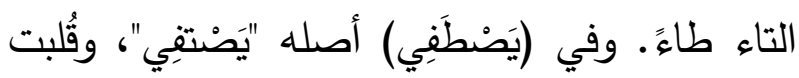

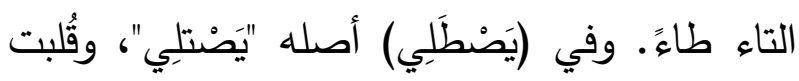

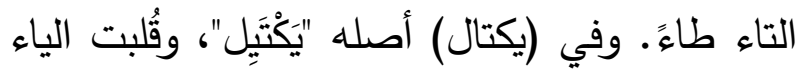
في وسط الفعل ألف مد. وكذلك في (يغتاب) أصله "يَغَتَِبَ"، وقُلبت الياء في وسط الفعل ألف مد. - الإدغام: الفعل (يتبع) أصله "يتَتُعَ"، بتاء ساكنة ثم تاء مفتوحة، فأدغت التاءان، فأصبحتا تاءة التاء

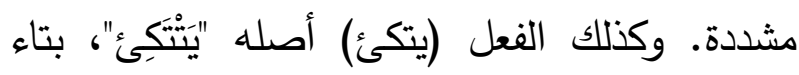
ساكنة ثم تاء مفتوحة، فأدغدت التاء ان، فأصبحتا تاء

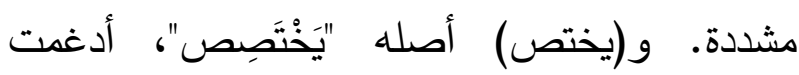

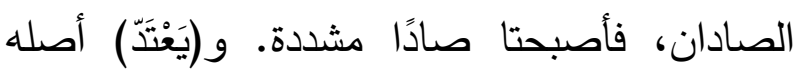
"تَعَعَدِد"، ثم أدغدت الدالان، فأصبحتا دالا مشددة.

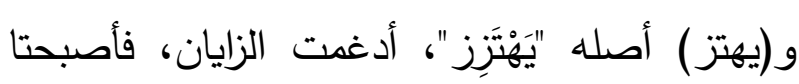

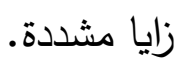


وأما (اكتسب) فهو التصرف والطلب والاجتهاد بمنزلة الاضطراب"(•) (اكتب)

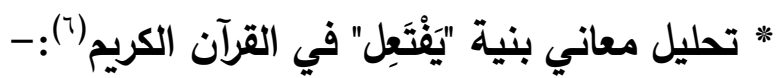

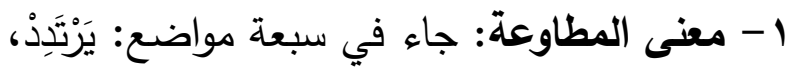

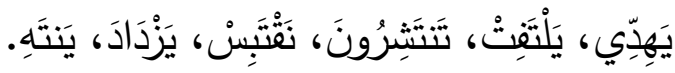

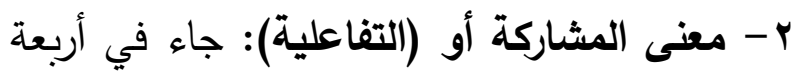

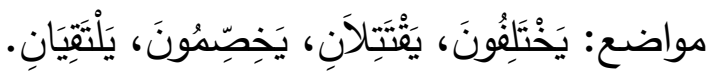

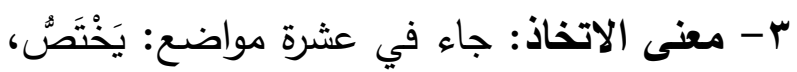

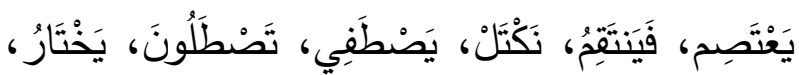

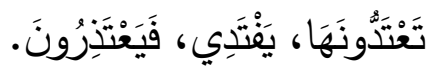
ع - معنى الخطفة: جاء في موضعين: يَلْتَطْلْهُ، تَنَهَنَّهُ.

ه- زيادة معنى الافتعال: جاء في تسعة وثلاثين

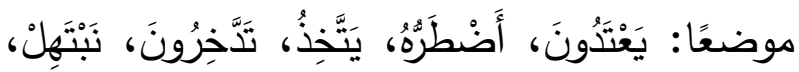

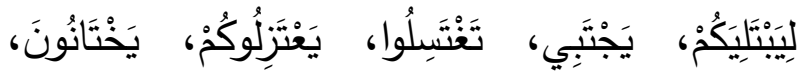

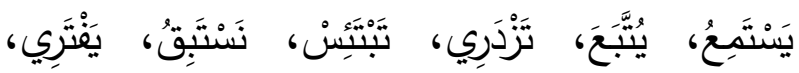

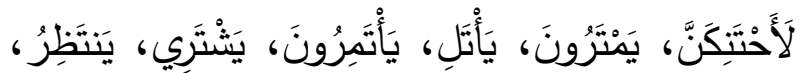

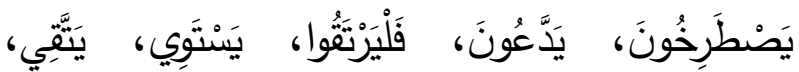

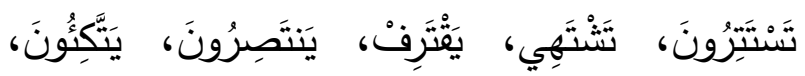

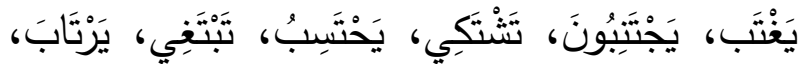
تَطَّلَعُ. ويُلحظ هنا أن زيادة معنى الافتعال هي الأكثر ورودًا

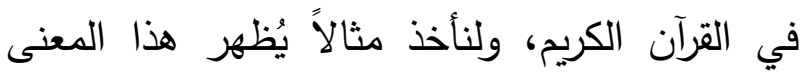

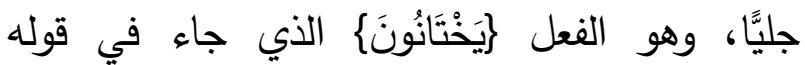

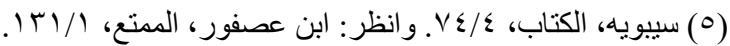

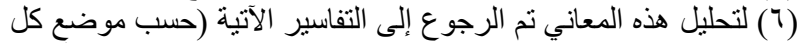

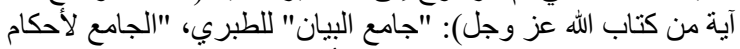

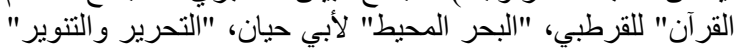

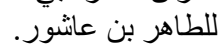

فاتصل، لا: انوصل (').

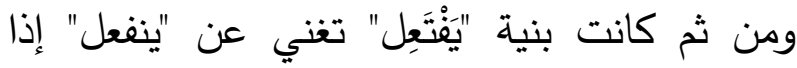
كانت فاء الفعل من حروف كلمة (ونرمل)؛ خشية

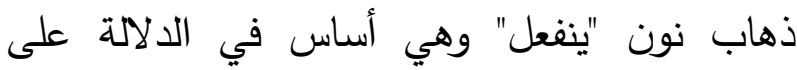

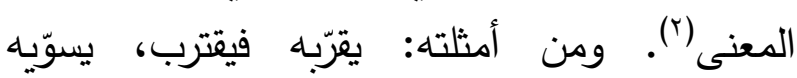
فيستوي، يكسوه فيكتسي، ينثره فينتر ، ينقله فينتقل،

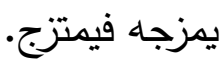
ץ- معنى المشاركة أو (التفاعلية): وهو أن يأتي

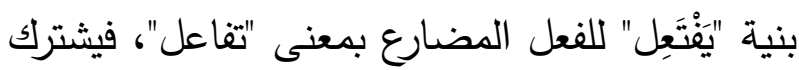

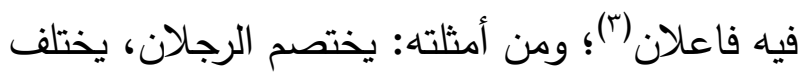

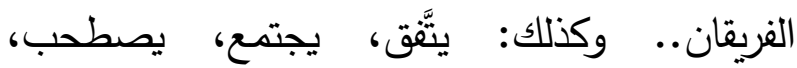
يصطدم، يصطلح، يقتتل، يقتسم. ץ- معنى الاتخاذ: وهو أن يقترن معنى الفعل بعل المضارع "يتخذ" مع معنى الفعل الآخر الذي يكون

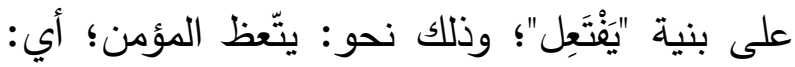

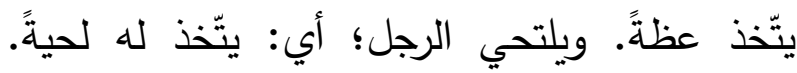
ومنها أيضاً: يحتجب، يحترس، يحترف، يحتكم،

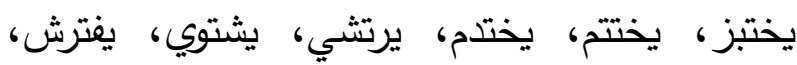

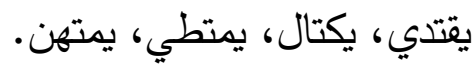

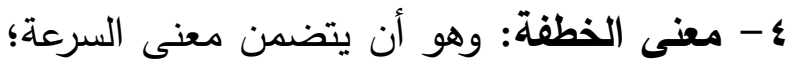

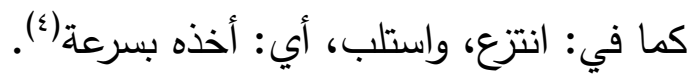

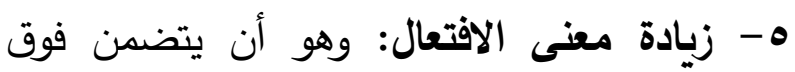

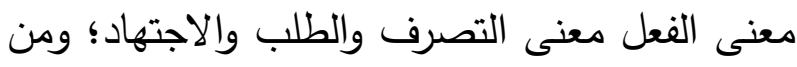
ذلك قول سيبويه: "وأما (كسب) فإنه يقول: أصاب.

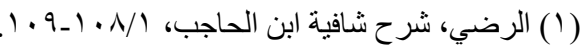

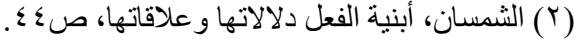

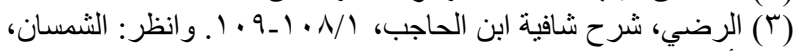

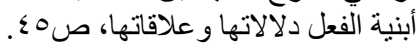

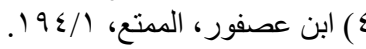


تظهر سرقته ردى بها في دار رجل يهودي، فلما وجدت الدرع عند اليهودي أنكر أن يكون أخذها، وأصر السارق الحقيقي أن اليهودي أخذها، واستعان بقوم من المسلمين على اليهودي، واستدل بأن الدرع وجدت عند اليهودي، فمال رسول الله -صلى الله عليه وسلم- إلى قولهم، فأطلعه الله على السارق وبرأ اليهودي، ونهاه عن مخاصمة اليهودي، وأمره بالاستغفار مما كان منه من معاونته الذين كانوا يتكلمون عن السارق(£). وهذه الحادثة ليست حادثة عابرة، إنما هي وقفة يخرج منها منهاج حياة يضيء الطريق للسالكين، فاللحظات عصيبة، والأحداث فارقة، والأيام تشهد مؤامرات متتابعة لليهود على النبي صلى الله عليه وسلم وأصحابه، والحادثة وقعت بين رجل من موات الأنصار الذين يدافعون عن النبي صلى الله عليه وسلم ليل نهار، وبين رجل من اليهود الأعداء المتآمرين الذين يمثلون خطرًا حقيقيًّا على الإسلام والمسلمين، وفي وقت لا يسمح بتشويه صورة المسلمين، والإسلام في بداية نشأته في المدينة، والسرقة حدثت في أمر يسير؛ وهي درع صغيرة لا تسمن ولا تغني من جوع.. كل هذه الأسباب وغيرها تجعل البشر يتجاوزون في أحكامهم، أو يحلون الأمور كما نقول بطريقة ودية، أو غير ذلك من الحلول التي يستسيغها الناس، أو أون يقبلون بها، في مثل هذه الحالات.. لكنَّ المنهج الإسلامي في أسمى درجات الرقي التي لا تصل

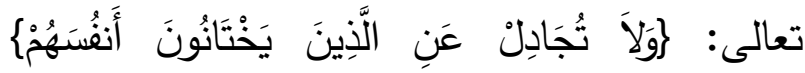

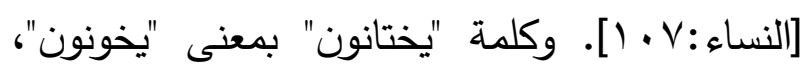
والقرآن الكريم حين يعدل عن "يخونون أنفسهم" إلى ولى "يختانون أنفسهم"، فلا بد أن لهذا معنى كبيراً؛ لأن

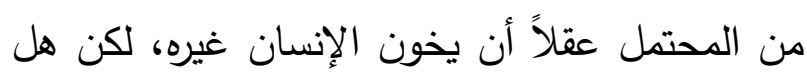

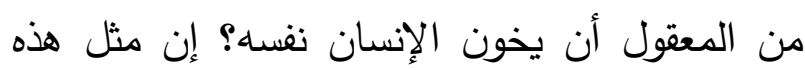
العملية تحتاج إلى افتعال كبير وإذا ما خان الإنسان نفسه فهذا ليس سهلاً ويتطلب افتعالاًً('). و (يختان) أصلها "يَخْتَوِن"، على وزنَ "يَفْتَعِل". وأصل هذه الكلمة مكوّن من حرف الخاء وحرف الواو وحرف النون (خ و ن). وهذه المادة اللغوية في كل صورها في القرآن الكريم تدور حول معنى النقص(؟)؛ ولذلك سُمِّي "نُقصانُ الوَفاء": خيانة. وناقض العهد: خائن؛ لأنه كان ينتظر منه الوفاء فغدر • والخيانة: هي نقضٌ لما وقع عليه تعاقد بدون إعلان مسبق بذلك النقض. والخيانة ضد الوفاء. والخيانة أصلها النقصُ، والوفاء أصله التمام (r). وقد جاءت مادة (خ و ن) في سورة النساء ثلاث مرات في سياق واحد: لِلََْائنِينَ، يَخْتَانُونَ، خَوَّانًا. قال

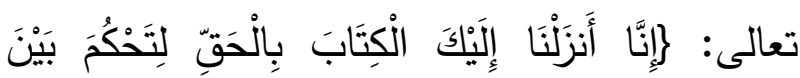

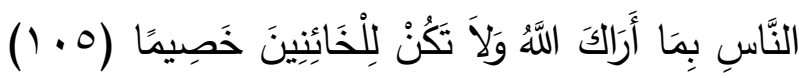

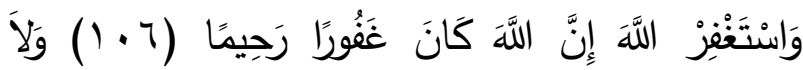

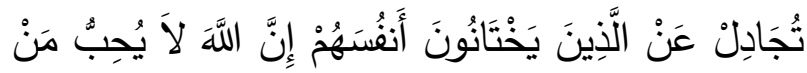

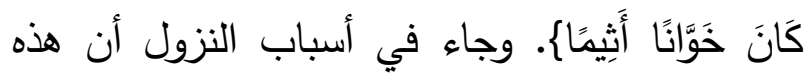
الآيات أنزلت في رجل سرق درعًا، فلما خاف أن 
التي فطر الناس عليها. وقد كانت هذه الآيات دليلا

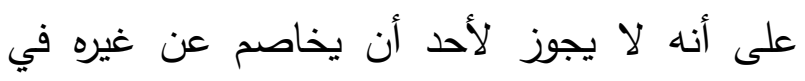
إثبات حق أو نفيه وهو غير عالم بحقيقة أمره لأن

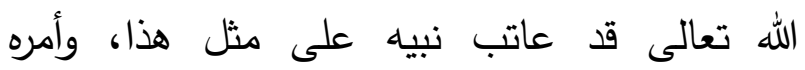
بالاستغفار منه. وكذلك كانت هذه الآيات دليلا على تلى تلى تلى أن التربية الحقيقية للمجتمع المسلم المؤهل لقيادة

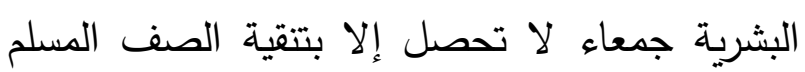

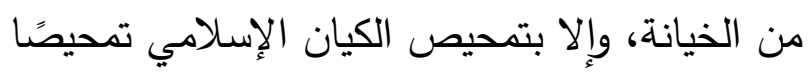
حقيقيَّا يُقيم به كل مسلم ميزان العدل داخل نفسيه.

إليها شريعة إلا شريعة رب العالمين، يعلن الحقيقة

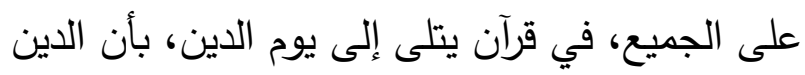

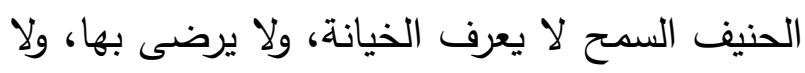

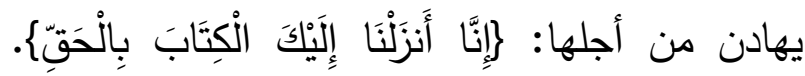
فهذا هو ميزان الإسلام الذي لا يتأثر بقرابة، ولا

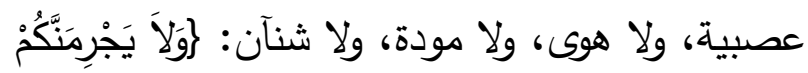

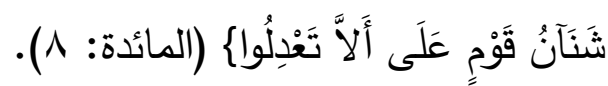

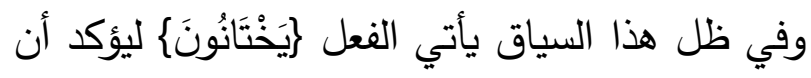
الذي يقدم على فعل مثل هذه الخيانة إنما يتطلب خيانة نفسه، بما في ذلك من جهد مخالف لفطرة الله المبحث الثاني: "تَفَاعل" ومواضعها في القرآن الكريم

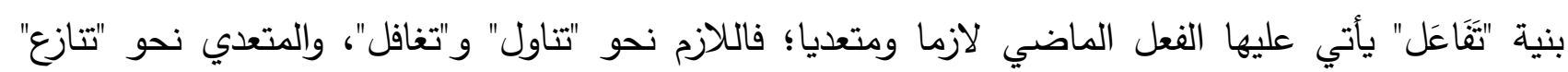
و"تجاذب".

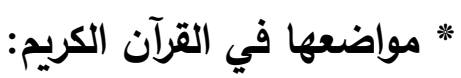

جاء وزن "تَفَاعَل" في إحدى وعشرين كلمة في القرآن الكريم؛ يجمعها الجدول الآتي ('):

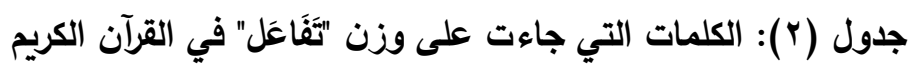

\begin{tabular}{|c|c|c|c|c|c|}
\hline الموضع & الكلمة & الموضع & الكلمة & الموضع & الكلمة \\
\hline تَرَاضَوَوْا & تراضى & 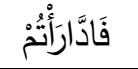 & تدارأ & تَثَابََة & تثابه \\
\hline بَتَازَعَعْتُمْ & تتازع & تََبَايَعْنُمُْ & تبايع & تَذَايتنتُ & تداين \\
\hline تَرَاءَى & تراءى & انثَََّقَلَنُمْ & تثاقل & تَقَاعَدَتُّمْ & تواعد \\
\hline فَفَطََاَوَلَ & تطاول & ادَّارَكَكَ & تدارك & تَعَالَى & تعالى \\
\hline فَفَتَعَاطَى & تعاطى & تَوَارَتْ & توارى & تَظَََهَرًا & تظاهر \\
\hline تَتَاسَسَرَتُُْْ & تعاسر & تَنَاَجَيَتُُْ & تناجى & فَفَمَارَوْا & تمارى \\
\hline تَوَاَصَوْا & تواصى & فَتَتَنَادوُا & تتادى & تََبَرَكَكَ & تبارك \\
\hline
\end{tabular}

* الحذف والققب والإدغام في مواضع "تَفَاعَل" في القرآن الكريم: 
ونصب الثاني. ومن ثمّ نَقَصَ "تَفَاعَل" مفعولًا واحدًا عن "فَاعَلَ". فإن كان "تفاعل" من "فاعل" المتعدي لمفعول به واحد صار لازما؛ نحو: ضارب علي زيدا. يصير : تضارب علي وزيد. وإن كان "تفاعل" هنول من "فاعل" المتعدي لمفعولين صار متعديا لمفعول به واحد؛ نحو: نازعته الأمر • يصبح: تنازعنا الأمر .

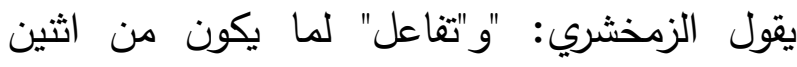

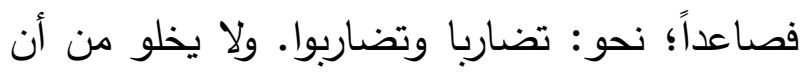
يكون من "فاعل" المتعدي إلى مفعول أو المتعدي وناري إلى مفعولين: فإن كان من المتعدي إلى مفعول

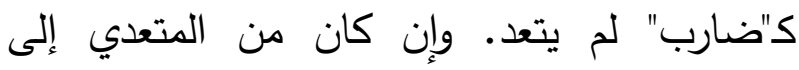
مفعولين؛ نحو: نازعته الحديث، وجاذبته الثوب، وناسيته البغضاء، تعدي إلى مفعول واحد، كقولك:

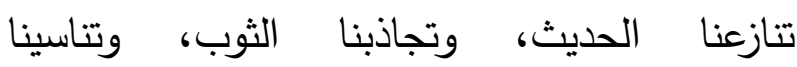

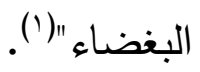

Y- معنى التظاهر: وهو أن يتظاهر الفاعل بحصول الفعل له، والأمر خلاف ذلك. يقول سيبويه: "وقد يجيء "تفاعلت" ليريك أنه في حالٍ ليس فيها. من ذلك: تغافلت، وتعاميت، وتعاييت، وتعاشيت،

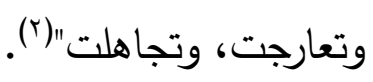

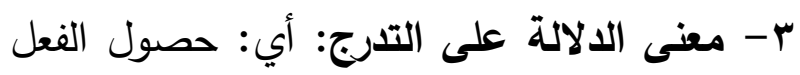
شيئًا فشيئا؛ نحو: تواردت الإبل، وتتامى المال.

ونحو: تزايد النيل؛ أي حصلت الزيادة تدريجيا(؟).

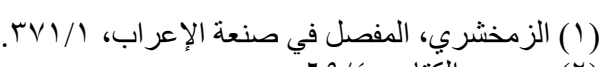

- حذف حرف العلة: في الفعل (تَرَاضَوْاً) حُذف حرف العلة من آخره؛ لاتصاله بواو الجماعة، وكذلك

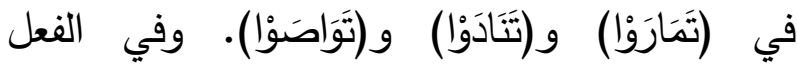
(تَوَارَتْ) حُذف حرف العلة من آخر الفعل؛ لاتصاله واله

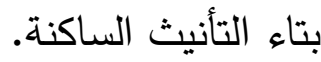
- القلب: في الفعل (تَنَاجَيْتُمُم) قُلب حرف العلة الألف المقصورة- في آخر الفعل ياءً؛ لاتصاله بتاء

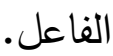
- القلب والإدغام: الفعل (ادَّارَأْ) أصله "تدارأ"، والفعل

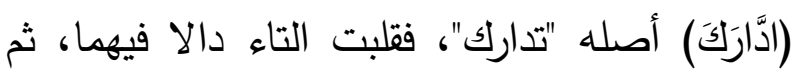
أُدغمت الدالان، فأصبحتا دالا مشددة، ثم جيء بهمزة الوصل للتخلص من الابتداء بساكن. وكذلك دأك

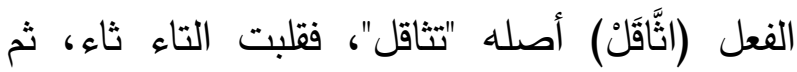
أُدغمت الثاءان، فأصبحتا ثاءً مشددة، ثم جيء بهمزة الثة الوصل للتخلص من الابتداء بساكن. * معاني بنية "تَفَاعَل" في القرآن الكريم:-

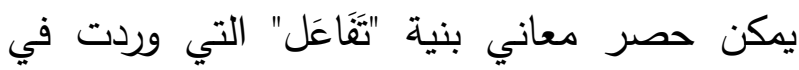
القرآن الكريم في خمسة معانٍ هي:1- معنى المشاركة (أو التفاعلية): نحو: هُنية تبارز الرجلان. ونحو: تصارع، وتقاتل. وهو يأتي لمشاركة

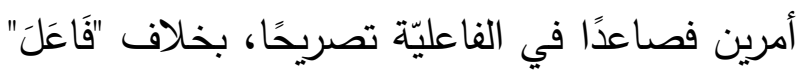
فإنّ نسبته بالفاعليّة إلى أحدهما صريحًا، وإلى الآخَرِ

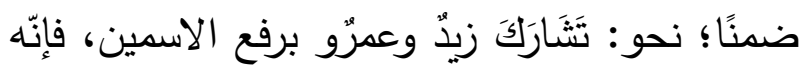
يدلّ على مشاركة اثثين في فاعليّة أصله. وأما:

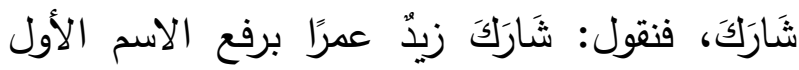


يُظهر هذا المعنى جليَّا، وهو الفعل (اثنَّقَتْنُم) في قوله

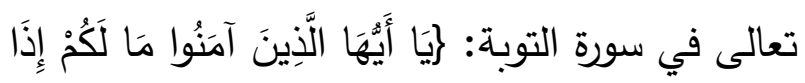

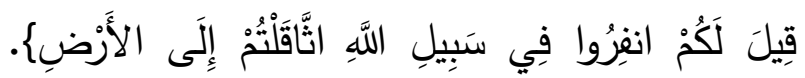

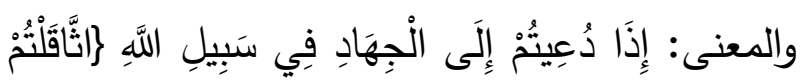

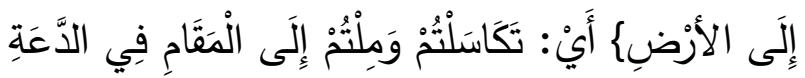

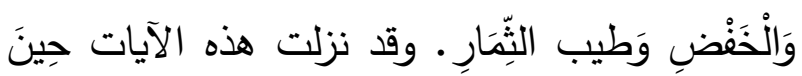

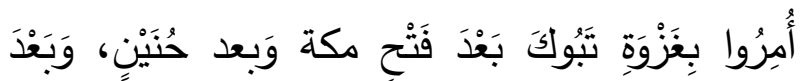

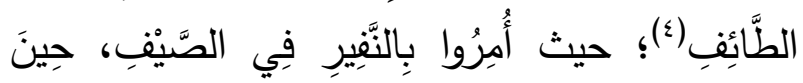

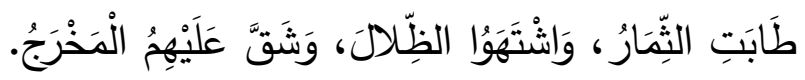

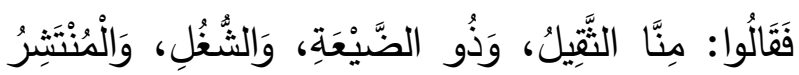

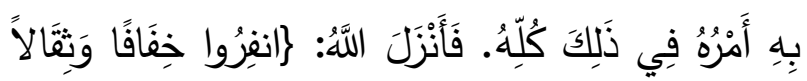

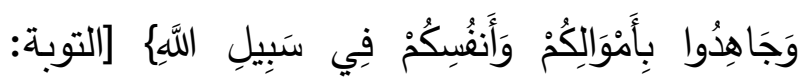

وأصل كلمة "تثاقل" مكوّن من حروف: الثاء والقاف واللام (ث ق ل)، وهذه الحروف الثلاثة إذا وُجدت في أصل كلمة فإن معناها يدور حول (معنى ضِدّ الخِفّة)(•). فالثِِّّل والخفّة معنيان متقابلان؛ فالشيء الحسي المادي الذي يرجح على ما يوزن به أو يقدّر به يقال عليه: ثَقِيل. وقد انتقل هذا المعنى إلى الأمور المعنويـة؛ فقيل لمن كثرت ديونه "أَقْقَتَه

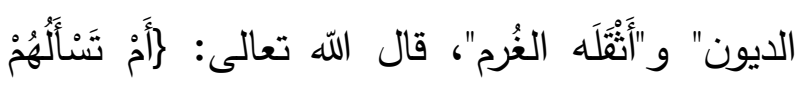

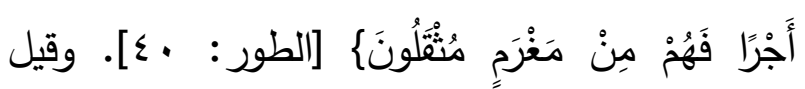

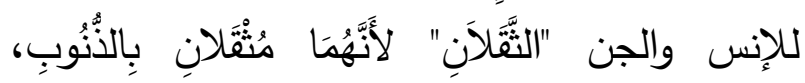
وقيل: سُمِّيَ الجنّ والإنس التُقَلينَ لكثرة العدد(؟).

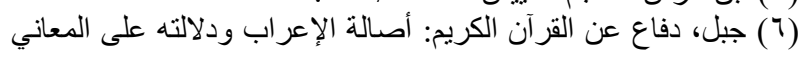

ع - معنى المطاوعة: نحو: باعدته فتباعد. يقول سيبويه: "وفي: فاعلته فتفاعل، وذلك نحو: ناولته

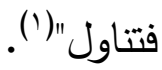
ه- معنى المبالغة: وهو أن يتضمن فوق معنى الفعل زيادة معنى المبالغة؛ نحو: تعالى الله عما يشركون. يقول سيبويه: "وقد يجيء "تفاعلت" على غير هذا، كما جاء في عاقبته ونحوها، لا تريد بها الفعل من اثنين"(r). * تحليل معاني بنية "تَفَاعَل" في القرآن الكريم(؟).:1 - معنى المشاركة بالفعل (أو التفاعلية): جاء في

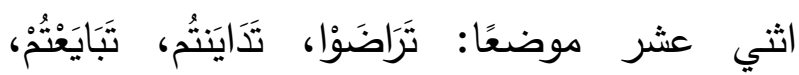

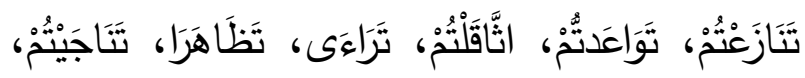
تَعَاسَرْتُنُه، فَتَنَادَوْا، تَوَاصَوْوا. r - معنى التظاهر: جاء في موضع واحد: فَادَّارَأَتْْ. r- معنى الالالة على التدرج: جاء في أربعة

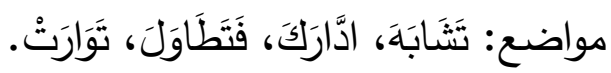
ع - معنى المطاوعة: جاء في موضعين: فَتَعَاطَى، لَّل، فَتَمَارَوْا . ه - معنى المبالغة: جاء في موضعين: تَعَالَى، تَبََرَكَكَ. ويُلحظ هنا أن معنى المشاركة بالفعل (أو التفاعلية) هو الأكثر ورودًا في القرآن الكريم، ولنأخذ مثالاً

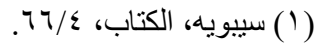

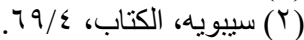

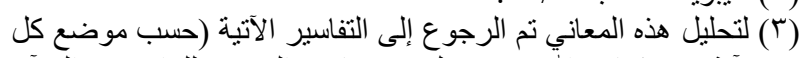

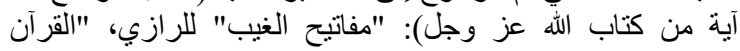

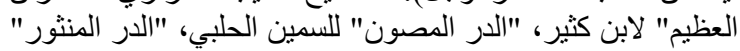

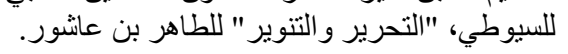


المبحث الثالث: "مَفْعَل" ومواضعها في القرآن الكريم بنية "مَفْعَل" بفتح العين تصاغ من الفعل الثلاثي، مرادا بها: المصدر والزمان والمكان. ومن أمثلتها:

مثوى، مسكن، ميمنة.

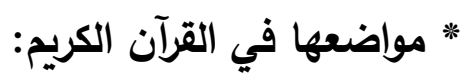

جاء وزن "تَفْعَ" في إحدى وخمسين كلمة في القرآن

الكريم؛ يجمعها الجدول الآتي ():

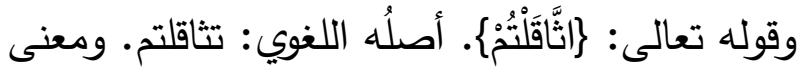
الفعل هنا يُعطي معنى المشاركة أو (التفاعلية)؛ كأنهم أخذوا يثقَّل كل واحد منهم الآخر فتئاقلوا

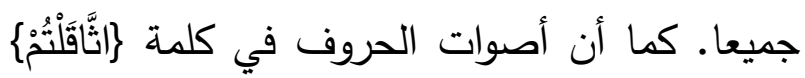
تعطي معنى لا تعطيه أصوات كلمة "تثاقلتم" وهذا باب عظيم من أبواب الإعجاز في القرآن الكريم؛ تعطيه

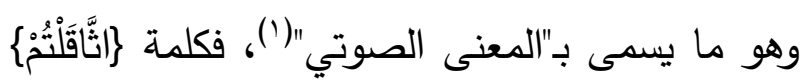
عندما تتطقها مقطعًا مقطعًا تسمعك جرسيًا صوتئًا يمثل الجسم المسترخي الثقيل الذي يرفعه الرافعون في جهد، فيسقط منهم في ثقل ملتصقًا بجاذبية الأرض! هذا التثاقل الذي تزيده المطامع، ويحدوه

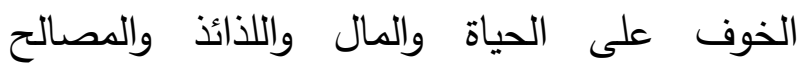
والمتاع، وكان الأنسب لمعنى هذا الجرس الصوتي ولتي

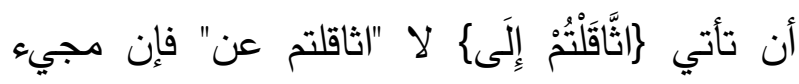
"إلى" هنا يجعل الفعل "اثاقلتم" يتضمن معنى الفي الفعل

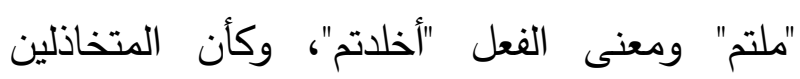
المخلفين مالوا إلى الأرض، وأخلدوا إليها ليتشبثوا

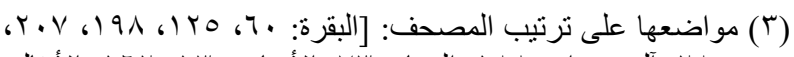

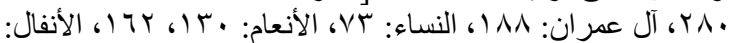
צ

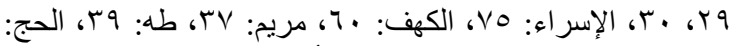
צV

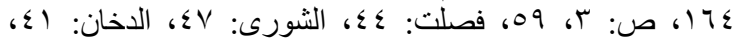

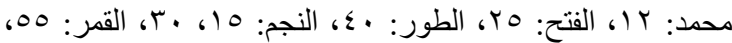

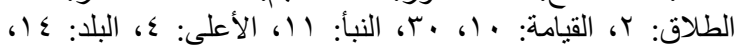
10] 0

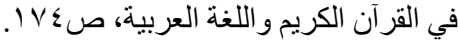

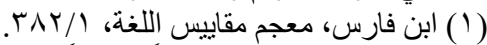

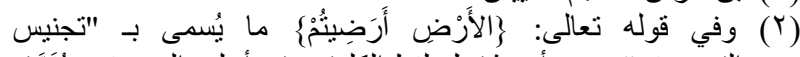

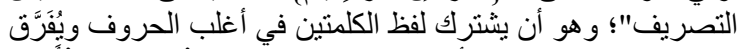

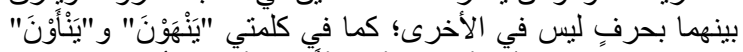

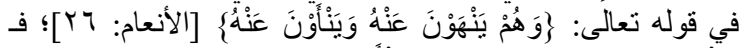

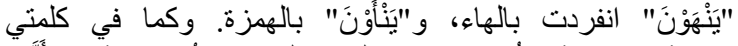

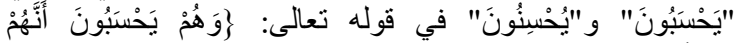

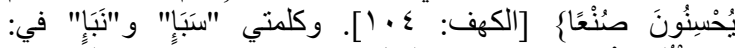

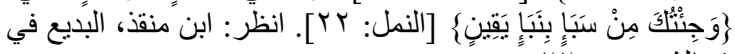

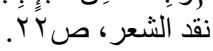


جدول (ץ): الكلمات التي جاءت على وزن "مَفْعَل" في القرآن الكريم

\begin{tabular}{|c|c|c|c|c|c|}
\hline الموضع & الكلمة & الموضع & الكلمة & الموضع & الكلمة \\
\hline الْمَشْعَرِ & مشعر & مَتًََبَةً & مثابة & مَشْرَرَبَهُمْ & مشرب \\
\hline بِِفَفَازَةٍ & مفاز & مَيْسَرَةٍ & ميسرة & مَزَْْاتِ & مرضناة \\
\hline مَحْيَايَ & محيى & مَعْشَرَ & معشر & مَوَدَّةُة & مودة \\
\hline مَأْمَنَهُ & مأمن & مَزْصَدِ & مرصد & كَنَامِكَ & منام \\
\hline مَجْرَاهَا & مجرى & مَخْمَصَةُة & مخمصة & مَغَارَاتٍ & مغارة \\
\hline مَتَّابِ & متاب & مَآبٍ & مآب & مَعَاذَ & معاذ \\
\hline مَشْهَهَدِ & مشهد & مَجْمَعَ & مجمع & الَََْْاتِ & ممات \\
\hline مَعَادٍ & معاد & مَنسَكَا & منسك & مَحَبَّةً & محبة \\
\hline مَّزَقَقَنَا & مرقد & مَسْكَنِهِنْ & مسكن & مَرَدَّ & مرد \\
\hline مَرْحَبًا & مرحب & مَنَاصٍ & مناص & مَعَّامُ & مقام \\
\hline مَوْلَّى & مولى & مَلْجَاٍِ & ملجأ & مَكَانٍ & مكان \\
\hline مَغْرَمِ & مغرم & مَعَرَّةُ & معرة & مَفْوَى & مثوى \\
\hline مَفْعَدِ & مقعد & مَبْلَغُهُم & مبلغ & الَْأَوَى & مأوى \\
\hline الْمَسَاقُ & مساق & الْمَفَرُ & مغر & مَخْرَجًا & مخرج \\
\hline مَسْغَبَةِة & مسغبة & الَْرَزعَى & مرعى & مَعَاشًا & معاش \\
\hline بِالْمَزحَحَمَة & مرحمة & مَتُرَبَةٍ & متربة & مَقْرَبَةٍ & مقربة \\
\hline مَطُلْعِ & مطلع & الَْشَأَمَةَةِ & مشأمة & الَْتْيَمَنَةِة & ميمنة \\
\hline
\end{tabular}

* القلب والإدغام في مواضع "مَفْعَل" في القرآن الكريم:

وأصلها "مَسْوَقَ"، و(معاش) وأصلها "مَعْيَش"، وفيها جميعها نقلت فتحة الواو إلى ما قبلها، ثم قُلبت الواو ألفف مد. وفي (مرضاة) وأصلها "مَرَضَوَة"، قُلبت أيضًا الواو ألف مد. - القلب والإدغام: جاء في (مودة) وأصلها "مَوْدَدة"، نقلت فتحة الدال الأولى إلى الواو قبلها، ثم أدغمت الدالان، فأصبحتا دالا مشددة. وكذلك في (محبة) - القلب: جاء في (مثابة) وأصلها "مَتَُْبَة"، و (مفاز) وأصلها "مَفْوَز"، و و(منام) وأصلها "مَنْوَم"، و و(مغارة) وأصلها "مَغْوَرَة"، و (معاذ) وأصلها "مَعْوَذَ"، و(مآب)

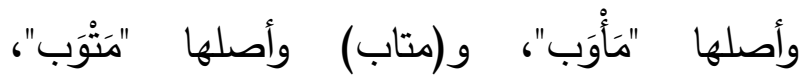

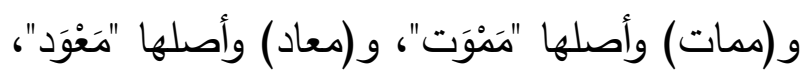
و (مقام) وأصلها "مَتََْم"، و و(مناص) وأصلها "مَنْوَص"، و و(مكان) و وأصلها "مَكْوَن"، و و(مساق) 
وأصلها "مَحَبَبة"، نقلت فتحة الباء الأولى إلى الحاء مسكن.

* تحليل معاني بنية "مَفْعَل" في القرآن الكريم("):معنى المصدرية فقط جاء في خمسة مواضع:

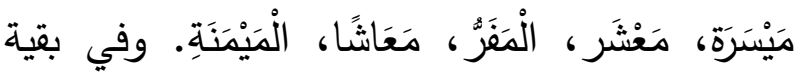

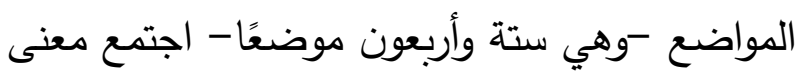

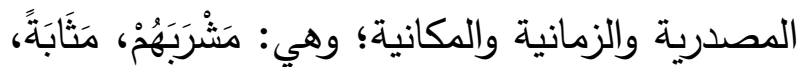

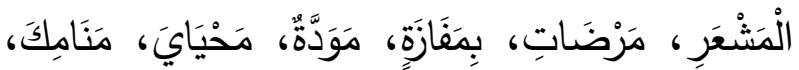

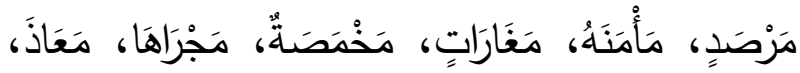

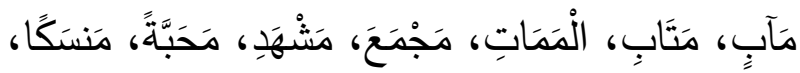

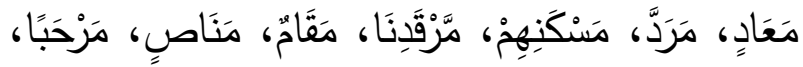

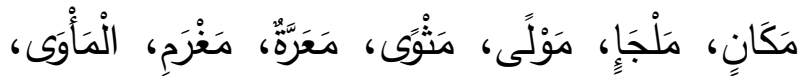

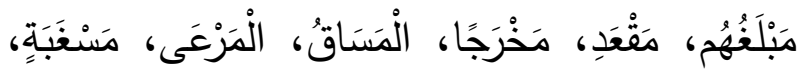

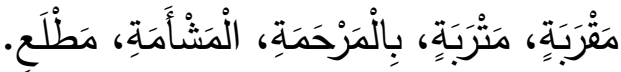

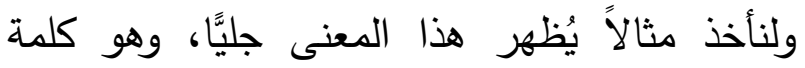

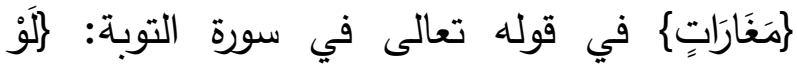

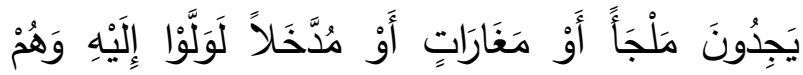

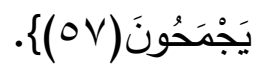
وأصل كلمة \}َمَغَارَاٍِ مكوّن من حروف الغين والواو

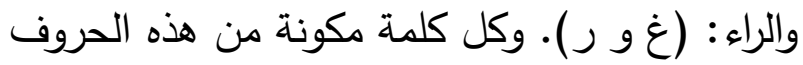
الثثلثة في القرآن الكريخ تجدها تجمع معان معاني: الانخفاض والانحطاط والسكون (๕). ومنه يُقِال: غَارَ

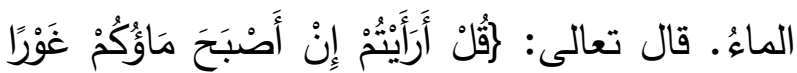

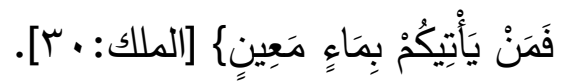

(r) لتحليل هذه المعاني تم الرجوع إلى التفاسير الآتية (حسب موضع كل

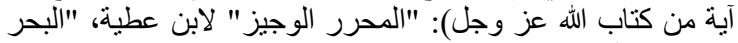
المحيط" لأبي حيان، "فتح القدير" للشوكاني، "التحرير و التنوير" لإن

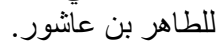

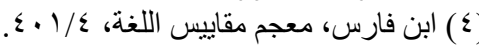

قبلها، ثم أدغدت الباءان، وفي (مرد) وأصلها "ترَزْدَد، نقلت فتحة الدال الأولى إلى الراء قبلها، ثم

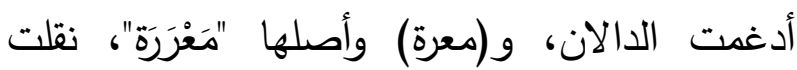
فتحة الراء الأولى إلى العين قبلها، ثم أدغمت التحان

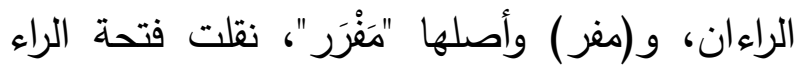
الأولى إلى الفاء قبلها، ثم أدغمت الراءاءن وان. * معاني بنية "مَفْعَل" في القرآن الكريم:-

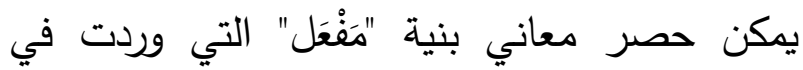
القرآن الكريم في معنيين؛ هما:1- معنى المصدرية فقط: تأتي بنية "مَفْعَل" بمعنى (المصدر) باجتماع شرطين: أن تكون لامها حرفا لهابه

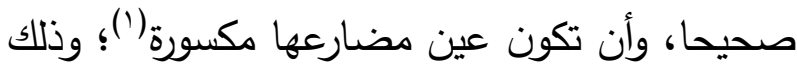

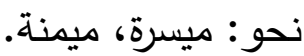
ץ - معنى (المصدر والزمان وإلمكان): تتضمن بنية

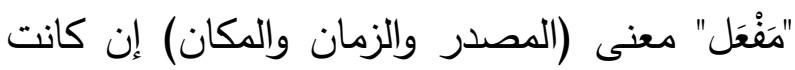
لامها حرف علة، أو إن كانت اللام حرفا صحيحا ولم تكن عين مضارعه مكسورة(Y):-

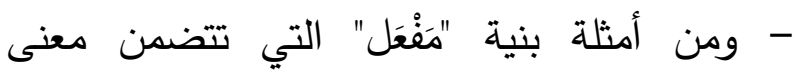
المصدرية والزمانية والمكانية (لأن لامها حرف لانيه لهان علة): مأوى، مثوى.

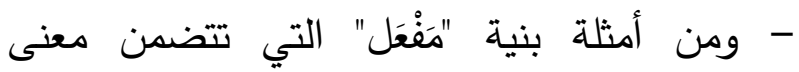

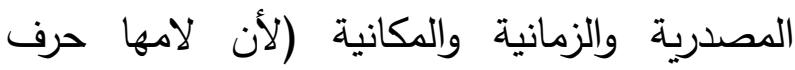
صحيح، وعين مضارعها غير مكسورة): مأمن، 


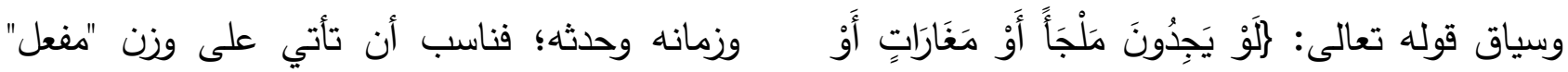

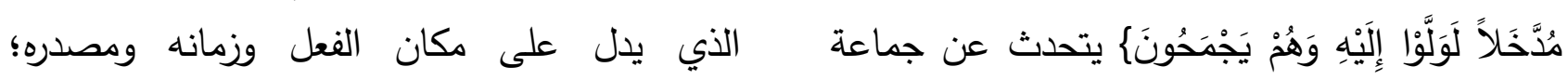

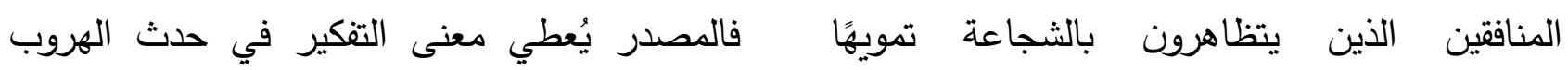

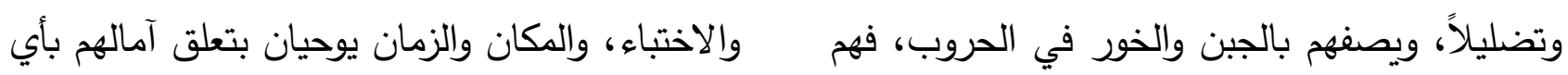
ككان يحميهم ويعتقدون أنه هو الذي سيسترهم أيَّا

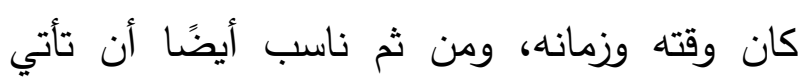
بصيغة الجمع كَغَارَاتِئ. * نتائج الاراسة:- جاء وزن "يَفتَعِل" في اثنتين وستين كلمة في القرآن الكريم. - يمكن حصر معاني بنية "يَفْتَعِل" التي وردت في التحري

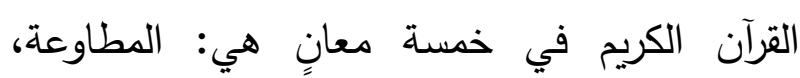
والمشاركة أو (التفاعلية)، والاتخاذ، والخطفة، وزيادة معنى الافتعال.

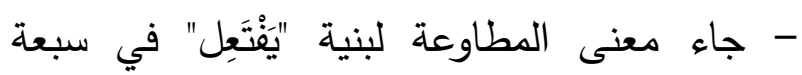

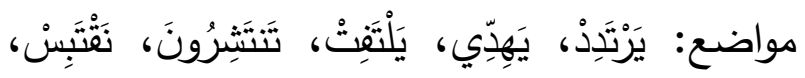

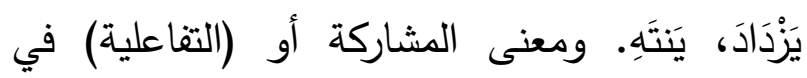

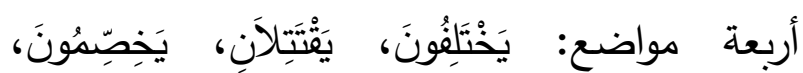

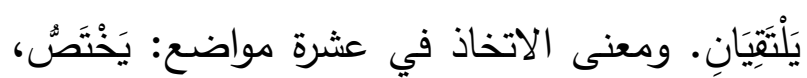

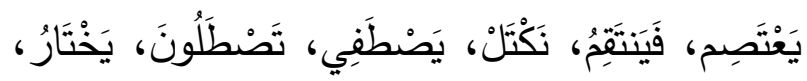

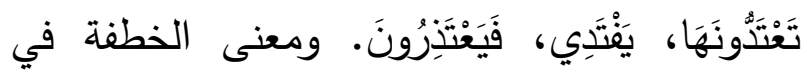

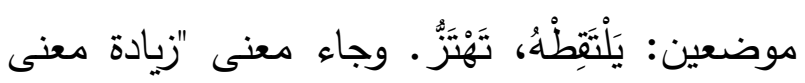

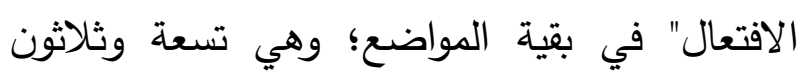
موضعًا.

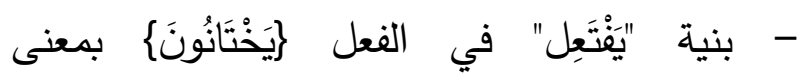
"يخونون"، في قولهه تعالى: 
القرآن الكريم في معنيين: معنى المصدرية فقط، ومعنى (المصدر والزمان والمكان) معًا. - بنية "مَفْعَل" يراد بها المصدر أو الزمان أو المكان إن كانت اللام حرف علة، أو كانت حرفا صحيحا غير مكسورة في عين مضارعه، فإن كُسرت عين مضارعه لِ تدل بنية "مَفْعَل" بفتح العين إلا على

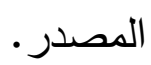

- جاء معنى المصدرية فقط لبنية "مَفْعَل" في خمسة مواضع: ميسرة، معشر، مفر ، معاش، ميمنة. وجاء معنى (المصدر والزمان والمكان) معًا، في بقية المواضع؛ وهي ستة وأربعون موضعًا.

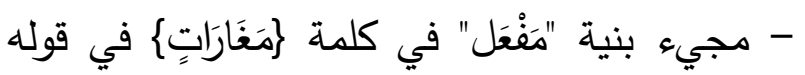
تعالى

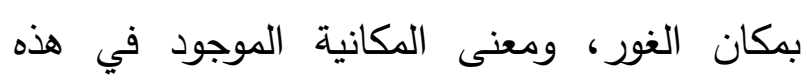
البنية؛ فكان الأنسب هو مجيء بنية "مَفْعَل" في سياق الحديث عن المنافقين (مَغَارَاتٍ عُ على خلاف ما جاء في قوله تعالى : رإِذْ هُمَا فِي الْغَارِئ. - وتوصي الدراسة بإجراء دراسات تحليلية استقرائية تتناول أبنية صرفية أخرى للكثف عن دورها الدلالي في كلمات القرآن الكريم.

\section{المراجع}

ابن الحاجب، جمال الدين أبو عمرو عثمان بن عمر الدويني. 990 (م. الشافية في علم التصريف. تحقيق: العثان، حسن أحمد. الطبعة الأولى، نشر المكتبة المكية، مكة المكرمة. ابن السراج، أبو بكر محمد بن سهل النحوي
أن الذي يقدم على فعل مثل هذه الخيانة إنما يتطلب خيانة نفسه، وهو أمر ليس سهلاً، بل يتطلب مشقة وافتعالاً. - جاء وزن "تََاعَل" في إحدى وعشرين كلمة في

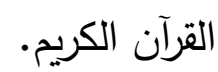
- يمكن حصر معاني بنية "تََّاعَل" التي وردت في القرآن الكريم في خمسة معانٍ هي: المشاركة أو (التفاعلية)، والتظاهر، والدلالة على التدرج، والمطاوعة، والمبالغة. - جاء معنى المشاركة (أو التفاعلية) لبنية "تََّاعَل" في اثني عشر موضعًا: تَرَاضَوْا، تَََايَتُم، تَبَايَعْنُنه،

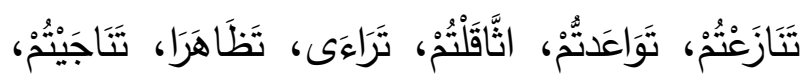

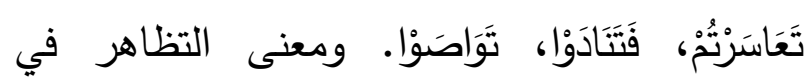

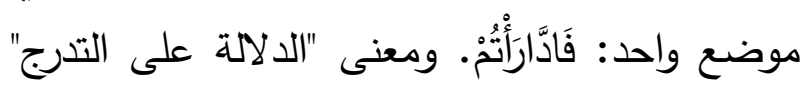

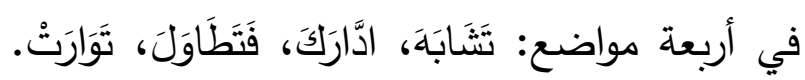
ومعنى المطاوعة في موضعين: فَتَعَاطَى، فَتَمَارَوْا. ومعنى المبالغة في موضعين: تَعَالَى، تَبَارَكَكَ.

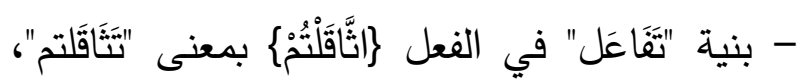

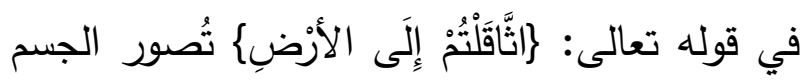
المسترخي الثقيل الذي يرفعه الرافعون في جهد، فيسقط منهم في ثقل ملتصقًا بجاذبية الأرض، وكأن المتخاذلين المخلفين مالوا إلى الأرض، وأخلدوا إليها ليتشبثوا بها. - جاء وزن "مَفْعَل" في إحدى وخمسين كلمة في

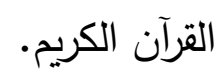
- يمكن حصر معاني بنية "مَفْعَل" التي وردت في 
ابن كثير، أبو الفداء إسماعيل بن عمر بن كثير

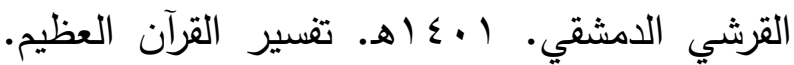
بدون رقم الطبعة، دار الفكر ، بيروت، لبنان. ابن مالك، جمال الدين أبو عبدالله محمد بن عبدالله الطائي الجياني. 97 ام. تسهيل الفوائد وتكميل المقاصد. تحقيق: بركات، محمد كامل. الطبعة الأولى، دار الكاتب العربي، القاهرة، مصر. ابن منظور ، أبو الفضل جمال الدين محمد بن مكرم الأفريقي المصري. د.ت. لسان العرب. بدون رقم الطبعة، دار صادر ، بيروت، لبنان. ابن منقذ، أبو المظفر مجد الدين أسامة بن مرشد الكناني الكلبي الشيزري. د.ت. البديع في نقد الشعر • تحقيق: بدوي، أحمد أحمد، وعبدالمجيد، حامد. مراجعة: مصطفى، إبراهيم. بدون رقم الطبعة، الإدارة العامة للثقافة، الإقليم الجنوبي، وزارة الثقافة

والإرشاد القومي، الجمهورية العربية المتحدة. ابن هشام، جمال الدين أبو محمد عبد الله بن يوسف الأنصاري. د.ت. أوضح المسالك إلى ألفية ابن مالك. تحقيق: البقاعي، يوسف الثيخ محمد. بدون رقم الطبعة، دار الفكر، بدون بلد النشر • أبو حيان، أثير الدين محمد بن يوسف بن علي بن يوسف بن حيان الأندلسي. • ب أهـ البحر المحيط في التفسير • تحقيق: جميل، صدقي محمد. بدون رقم الطبعة، دار الفكر ، بيروت، لبنان. جبل، محمد حسن حسن. . . . بام. دفاع عن القرآن الكريخ: أصالة الإعراب ودلالته على المعاني في
البغدادي. 9^^وام. الأصول في النحو. تحقيق: الفتلي، عبدالحسين. الطبعة الثالثة، مؤسسة الرسالة،

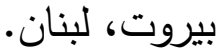
ابن القطاع، أبو القاسم علي بن جعفر السعدي المصري. سم9 (م. كتاب الأفعال. الطبعة الأولى، عالم الكتب، بيروت، لبنان. ابن جني، أبو الفتح عثمان. ع \& أه/900 ام. الخصائص. تحقيق: النجار ، محمد علي. بدون رقم الطبعة، دار الكتاب المصري، القاهرة، مصر • ابن عاشور، محمد الطاهر بن محمد بن محمد الطاهر التونسي. ع^و ام. التحرير والتتوير اتحرير المعنى السديد وتتوير العقل الجديد من تفسير الكتاب المجيد《. بدون رقم الطبعة، الدار التونسية للنشر، تونس. ابن عصفور، أبو الحسن علي بن مؤمن الحَضْرَمي الإشبيلي. 997 ام. الممتع الكبير في التصريف. الطبعة الأولى، مكتبة لبنان، بدون بلد النشر.

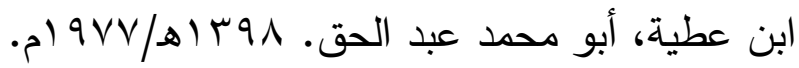
تفسير ابن عطية المسمى "المحرر الوجيز في تفسير الكتاب العزيز".تحقيق:الفاروق، الرحالي، والأنصاري، عبد الله بن إبراهيم. الطبعة الأولى، مؤسسة دار العلوم، القاهرة، مصر • ابن فارس، أبو الحسين أحمد بن فارس.

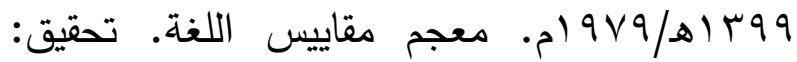
هارون، عبد السلام محمد. بدون رقم الطبعة، دار الفكر ، بدون بلد النشر • 
الزمخشري، أبو القاسم محمود بن عمر. بو99 ام. المفصل في صنعة الإعراب. تحقيق: بوملحم، علي. الطبعة الأولى، دار ومكتبة الهلال، بيروت، لبنان. السقاف، عَلوي بن عبدالقادر. بrإ اله. موسوعة

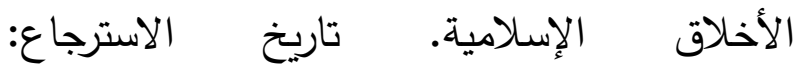

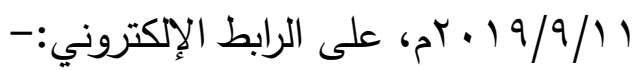
https://bit.ly/2QfGykz السمان، راتب عبدالوهاب. I1 1 • rم. الميزان الصرفي

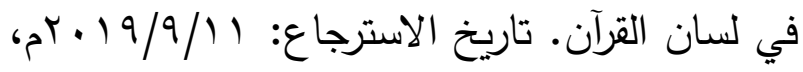
https://bit.ly/2KbNmvK

$$
\text { على الرابط الإكتروني:- }
$$

السمين الحلبي، أبو العباس شهاب الدين أحمد بن يوسف بن عبد الدائم. د.ت. الدر الدصون في علوم لتوبن

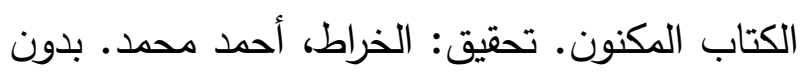

$$
\text { رقم الطبعة، دار القلم، دمشق، سوريا. }
$$

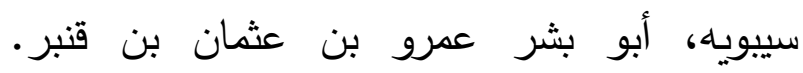

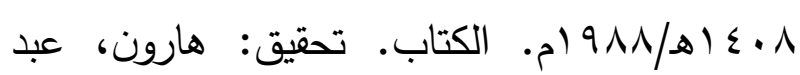

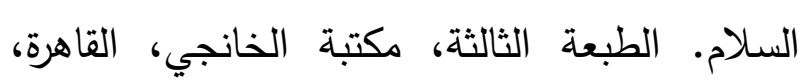

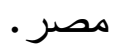
السيوطي، أبو الفضل جلال الدين عبد الرحمن بن

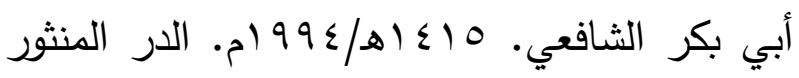
في التنسير بالمأثثر. الطبعة الأولى، دار الكتب

$$
\text { العلمية، بيروت، لبنان. }
$$

الشعراوي، محمد متولي. 99 ام. تفسير الشعراوي. بدون رقم الطبعة، مطابع أخبار اليوم، القاهرة.

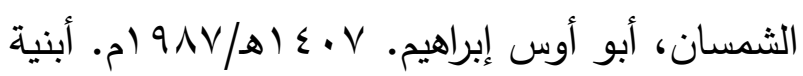
الفعل دلالاتها وعلاقاتها. الطبعة الأولى، مكتبة إنىاهيم.
القرآن الكريم واللغة العربية. بدون رقم الطبعة، البربري للطباعة، بسيون، الغربية، مصر .

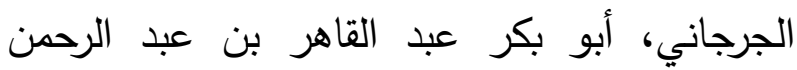

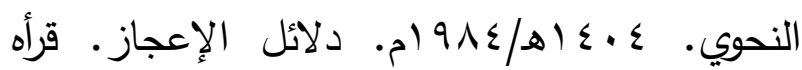
وعلق عليه: شاكر ، أبو فهر محمود محمد. الطبعة الأولى، مكتبة الخانجي، القاهرة.

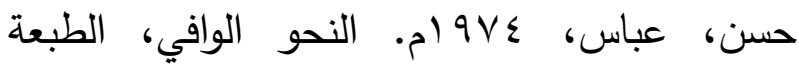
الثالثة، دار المعارف، القاهرة.

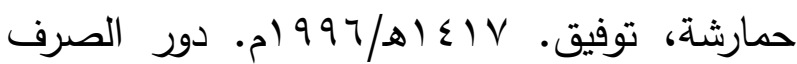

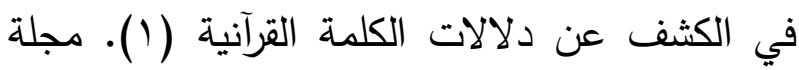
هدي الإسلام، وزارة الأوقاف والثؤون والمقدسات

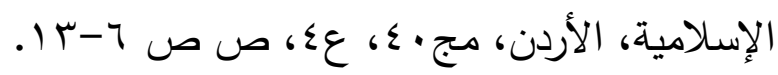

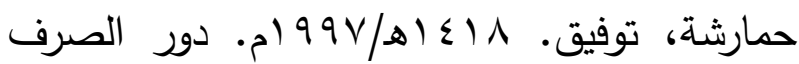
في الكثف عن دلالات الكلمة القرآنية (r). مجلة هدي الإسلام، وزارة الأوقاف والثؤون والمقدسات

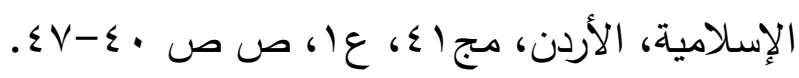

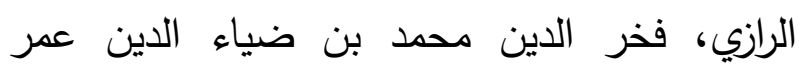

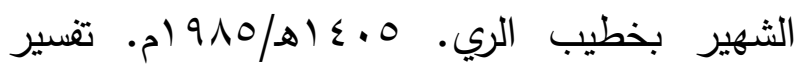
الفخر الرازي الثهير بالتفسير الكبير ومفاتيح الغيب.

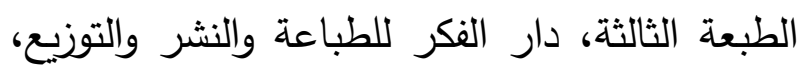

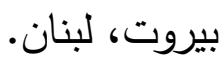
الرضي، نجم الدين محمد بن الحسن الإستراباذي. 0 9 ا هـ/9V0 ام. شرح شافية ابن الحاجب. تحقيق: الحسن، محمد نور، والزفزاف، محمد، وعبدالحميد، محمد محيي الدين. دون رقم الطبعة، دار الكتب العلمية، بيروت، لبنان. 
بوضياف، المسيلة، الجزائر •

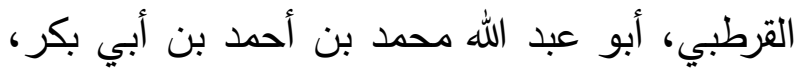

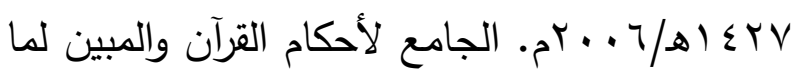

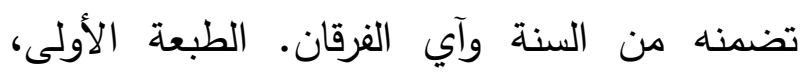
مؤسسة الرسالة، بيروت، لبنان.

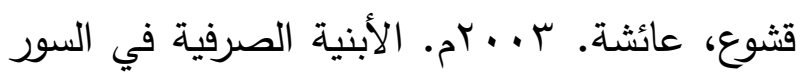
المدنية دراسة لغوية دلالية. رسالة ماجستير، كلية

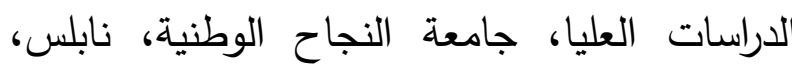

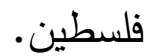

اللبدي، محمد سمير نجيب. 0. أهـ/910 ام. معجم المصطلحات النحوية والصرفية. الطبعة الأولى، مؤسسة الرسالة، دار الفرقان، ، بدون بلد

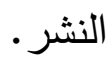

الواحدي، أبو الحسن علي بن أحمد النيسابوري.

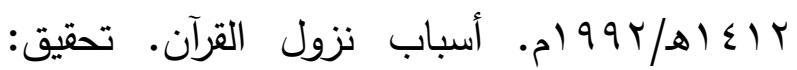

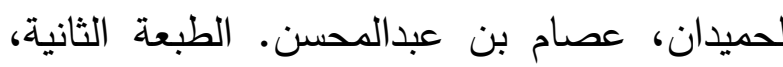
دار الإصلاح، الدمام، السعودية. يعقوب، إميل بديع. 991 ام. قاموس المصطلحات الإمدات اللغوية والأدبية. الطبعة الأولى، دار العلم للملايين،

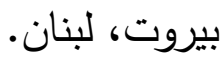

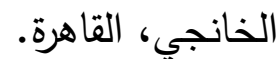

الشوكاني، محمد بن علي بن محمد. بهوبان الهـ.

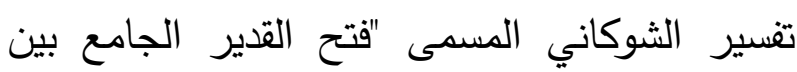
فني الرواية والدراية من علم التفسير". بدون رقم الطبعة، دار الفكر ، بيروت، لبنان.

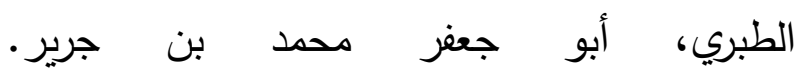

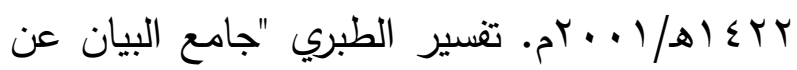

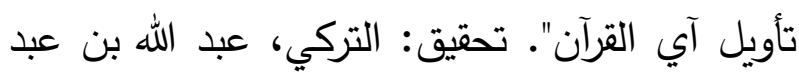
المحسن. الطبعة الأولى، مركز البحوث والديقي الدراسات

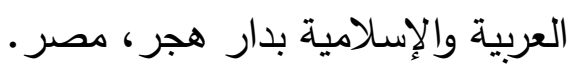

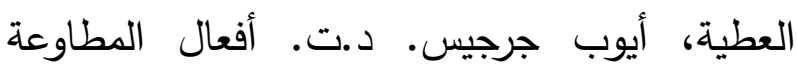
واستعمالاتها في القرآن الكريم. بدون رقم الطبعة، داته دار الكتب العلمية، بيروت، لبنان. عمر، أحمد مختار . 991 ام. علم الدلالة. الطبعة لئنان. الخامسة، عالم الكتب، القاهرة.

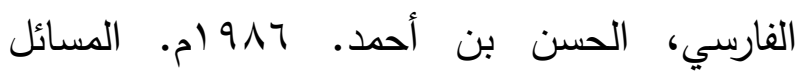
العضديات. تحقيق: الراشد، شيخ. بدون رقم الطبعة، دمشق، سوريا، ، بدون بيانات الناشر .

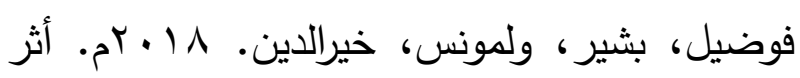
تتوع الصيغ الصرفية في إيضاح المقاصد القرآنية. رسالة ماجستير، كلية الآداب واللغات، جامعة محمد إئح المعاه 


\title{
Morphological Structures "Yafta'el, Tafa'al, and Maf'al" and Its Semantic role in Quranic Word An Analytical Applied Study
}

\author{
Dr. Ali Khalifa Atwa Abdul Latif \\ Assistant Professor of Arabic syntax and morphology, \\ King Faisal University, Saudi Arabia
}

\begin{abstract}
Holy Quran Explanation books about the three morphological structures "Yafta'el, Tafa'al, and Maf'al" and their role in defining the meaning of words in the Quran.

The aim of this work was to identify and analyze these morphological structures to determine letters omission or changes then applying the syntactic and meanings at the locations they were mentioned in to understand the meaning of the Qur'anic word through syntactic structure meanings.

The study adopted an analytical approach. It was composed of an introduction, preface, and three sections. The preface presents the study terminology and procedural definitions. The three sections were devoted to the three structures where the locations of each one was indicated followed by stating the omissions, letter changing, and fusion with an analysis and application for its meanings.

The main findings indicated that the structure "Yafta' $\mathrm{el}$ " is used to indicate the five meanings of obedience, responsiveness, adopting, speedy response, exaggerating. Meanwhile, the structure "Tafa 'al" is used to indicate the meanings of responsiveness, acting as if, progression, obedience, exaggerating. The structure "Maf'al" indicates the probable meanings of infinitive, tenses, or placement according to context, except for five words where it was used to indicate the infinitive only.
\end{abstract}

Key Words: Intransitive Verb, Passive Participle, Transitive Verb, Trilateral Verb. 